\title{
FEEDING EXPERIMENTS ON TADPOLES
}

\author{
II. A FURTher CONTRIBUtion TO THE KNOWLEDGE OF ORGANS \\ WITH INTERNAL SECRETION \\ J. F. GUDERNATSCH \\ Department of Anatomy, Cornell University Medical College, New York \\ (From the Department of Histology and Embryology, University \\ of Munich. Director: Prof. S. Mollier) \\ TWO DOUBLE PLATES
}

Certain mammalian glands with a so-called internal secretion, when given as food, can enact a decided influence on the growth and differentiation of amphibian embryos. This was shown by experiments that were carried out during the summer of 1911 on tadpoles of Rana temporaria and Rana esculenta.

During the spring of 1912 these experiments were repeated and at the same time varied to such an extent that no doubt as to their results remained. Although the experiments of the two seasons revealed many precise data, there is still a great number of obscure features regarding the definite action of internally secreting glands when fed to the tadpoles. While the influence on growth and differentiation resulting from feeding some of the glands was striking, others exerted no marked effects. The action of the latter, in part or entirely, may not be concerned with those most important physiological processes in the embryo, namely, growth and differentiation. They might play their chief rôle, then, in the household of the postembryonic organism. Or, since taken from mammals, some of these internally secreting glands, if at all connected with embryonic development, may fail to reveal this influence, when fed to amphibian embryos. Their action must finally be studied in experiments on higher vertebrates.

The experiments in 1912 were performed on tadpoles of Rana temporaria, Rana esculenta, Bufo vulgaris and Triton alpestris. 
The eggs of these species were collected from ponds in the vicinity of Munich and reared in the laboratory. They were kept in large aquaria and after hatching were transferred to smaller dishes, each dish containing about 100 individuals. After the larvae had grown for some time and seemed to be crowded in the dishes they were separated into smaller groups. To avoid possible errors, a great number of individuals was always used for each kind of experiment. All in all, over 20,000 tadpoles were treated.

The eggs from different localities were kept separate and, as far as possible, eggs apparently coming from the same mother were grouped in one set and used for a special experiment. Whenever the eggs necessary for one experiment could not all be supplied by a single female I endeavored to select eggs coming from the same locality, and apparently in the same stages of development. For example, set III probably contained eggs from three mothers, but the time of hatching, April 7 and 8, and their sizes, 10 to $11.5 \mathrm{~mm}$ at the beginning of the experiment, show them to be in similar stages of development. Again, for other experiments in which a large number of animals was required, as in sets VIII to XI over 4000, several sets in apparently the same stage of development were thoroughly mixed and then divided into smaller groups. In these last sets the tadpoles hatched between April 10 and 13 and a month later, when the feeding began, their sizes varied from 13 to $18 \mathrm{~mm}$; this difference is not greater than one would encounter in eggs from a single individual.

The water was changed at least once a day. While standing, its temperature varied with the room temperature, a process that corresponds to natural conditions. However, even in a room with apparently uniform temperature, the water will not show exactly the same temperature in all the dishes, as Barfurth has pointed out. To overcome any unequal influence of light, air and temperature resulting from the position of the dishes, they were shifted several times a day so as to progress in a certain order. With this precaution there were no detectable differences of temperature in the dishes assigned to one set. There was sometimes a slight difference of temperature between the dishes 
used for the different experiments, but this was of no importance, so long as the tadpoles used for one experiment were kept under uniform conditions.

As during the previous year, the food in small pieces was placed in the water and there voraciously taken by the animals, with the exception of pancreas which never seemed to excite their appetite very greatly.

Last year the tadpoles had their natural food previous to the experiments, this year in all but one experiment no other food was received except the one chosen for the studies. In 1911 after the feeding began the animals were kept exclusively on a onegland diet; in 1912 these experiments were repeated with part of the animals while in addition a mixed, either two-animal tissues or gland-plant diet, was introduced.

The following were used as foods: thyroid, adrenal, liver, spleen, hypophysis, brain, pancreas and muscle from the horse, testicle, ovary and thymus from cattle, and as vegetable food Elodea canadensis and Ceratophyllum demersum.

It would not have been possible to perform such an extensive series of experiments but for the courtesy and generosity of Prof. S. Mollier, in whose laboratory in Munich the experimental part of this paper was carried out. It is with pleasure that I express my best thanks for the many kindnesses shown me during my stay in his laboratory.

\section{Experiment I}

Rana temporaria, Set I. Figure 1, a to zf. Hatched April 4 to 7 , 1912. Feeding began April 13, 1912. Original size 10.2 to $12 \mathrm{~mm}$.

The diary reads as follows:

April 4 The feeding begins.

April 22 Thyroid-fed have hind legs forming.

April 24 Thyroid-fed have fore legs forming.

April 25 Thyroid-fed begin to die off.

April 29 Last thyroid-fed animals dead. Thymus- liver- spleen- and muscle-fed tadpoles are larger than the other groups.

April 30 Muscle, liver and spleen ones show hind leg buds.

May 4 Adrenal cortex, adrenal medulla and ovary have hind leg buds faintly noticeable. 


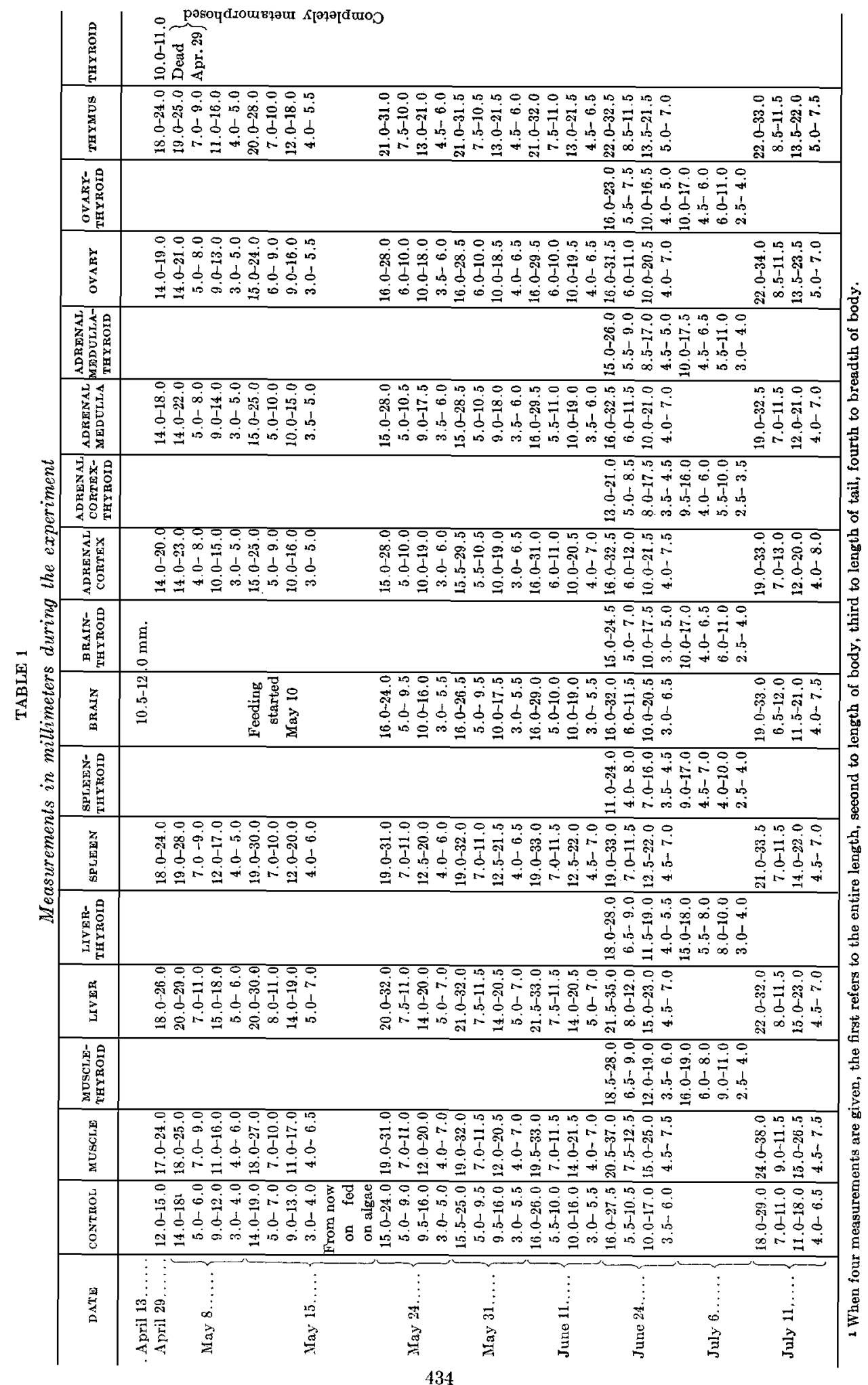


Niay 14 To this time the controls have been starving, in order to test the possible influence of hunger on development. They show no signs of advancement, but are far behind in size. From now on they are fed on Elodea canadensis.

A group originally intended for a hypophysis diet also starved up to this day, and from now on is fed on brain.

The liver-fed ones have a greenish color, the thymus-fed animals are deep black.

May 24 The smallest individuals in all sets begin to die off. The spleen-fed ones become very black, the bigger ones on adrenal cortex become very light, lighter than on adrenal medulla.

June 12 The first liver-fed ones show hind legs; this is 49 days later than the time at which the thyroid-fed ones attained the same condition.

June 14 Hind legs appear in adrenal-cortex-fed tadpoles. Their body assumes a peculiar triangular shape (fig. $7 b$ ), very pointed at the anterior end and broad at the posterior. They are all becoming light, while all the adrenal-medulla-fed ones are dark.

June 17 A number of each group, 70 to 80 , which have no hind legs except the small buds, are placed on thyroid diet.

June 19 The light color of the adrenal-thyroid tadpoles is disappearing.

June 20 Those liver-fed ones that have put out fore legs since June 12 shorten their tails.

The liver-thyroid animals develop hind legs.

June 21 Adrenal medulla-thyroid and muscle-thyroid tadpoles develop hind legs. The former are extremely active.

June 22 Liver-thyroid and muscle-thyroid ones assume a frog shape.

June 23 Spleen-thyroid and adrenal cortex-thyroid ones develop hind legs. The first liver-fed frog leaves the water.

June 24 Spleen-thyroid and adrenal cortex-thyroid animals assume frog shape. Brain-thyroid ones develop hind legs. Adrenal cortex tadpoles are extremely light greenish-yellow.

Brain-fed ones assume somewhat the triangular adrenal cortex shape described on June 14.

June 25 Liver-thyroid and adrenal medulla-thyroid animals show fore legs.

June 26 Spleen-thyroid-fed ones show fore legs.

Ovary-thyroid and brain-thyroid tadpoles assume frog shape, the latter are very active.

June 27 Muscle-thyroid animals show fore legs.

June 29 Adrenal cortex-thyroid and brain-thyroid ones show fore legs.

June 30 Ovary-thyroid ones show fore legs.

July 6 All the thyroid-fed ones are fixed, since many of them die.

July 7 Brain-fed tadpoles show hind leg buds. 
July 11 Muscle-fed ones have the best developed hind legs, next the ovary and adrenal-cortex ones which have short but very strong legs, then adrenal-medulla, brain and spleen.

The color of the animals on the different diets is: control, brown; musele, dark brown; liver, dark greenish; spleen, dark; adrenal cortex, very light brown; adrenal medulla, dark brown; ovary, yellowish; thymus, dark; brain, brown.

July 19 Muscle-fed ones begin metamorphosing.

July 20 Ovary-fed ones begin metamorphosing.

Thymus-fed have no signs of legs, spleen-fed only small buds.

In this experiment the thyroid treatment proved to be as effective as in the experiments performed in 1911. Tadpoles that had been fed on no other food than thyroid grew hind legs 9 days after the feeding began and fore legs only 2 days later. Normally several weeks would have elapsed between the appearance of the hind and the fore extremities. When these thyroid-fed tadpoles put out their anterior limbs and began to shorten their tail, they were 18 to 20 days old, calculating from the date of hatching. Normally they would take from 10 to 12 weeks to complete their metamorphosis.

The tadpoles fed on ordinary meat, muscle (fig. $1 d, 1 n$ ), showed distinct hind legs 44 days and fore legs 71 days later than the thyroid-fed ones. The first individual in the musclefed group to complete its metamorphosis was approximately 104 days old.

Liver-fed tadpoles (fig. $1 a, 1 i, 1 x$ ) show the best growth, although their growth is only slightly better than that of the spleen and thymus sets. Next to the thyroid group the liver-fed tadpoles also showed most rapid progress in differentiation. They grew hind legs 40 days and fore legs 49 days later than the thyroid group. The first liver-fed specimen to complete its metamorphosis was approximately 78 days old.

The spleen- (fig. $1 b, 1 l$ ) and thymus- (fig. $1 c$ ) fed tadpoles show almost parallel courses in growth and differentiation. During the first weeks of the experiments the spleen group ran a little ahead of the thymus specimens. The members of both groups became extremely dark in color during the course of the feedings. At the approximate age of 104 days, when the experi- 
ment was discontinued, none in either group had hind legs out, although spleen-fed ones showed leg buds.

The three groups of tadpoles fed on adrenal cortex (fig. $1 f, 1 r$ ), adrenal medulla (fig. $1 g, 1 t$ ) and ovary (fig. $1 e, 1 p$ ) were during the first weeks of growth behind the muscle, liver, spleen and thymus groups. Later, however, they grew more rapidly. Some of those fed on ovary actually reached the average size of the faster groups and completed their metamorphosis at the approximate age of 105 days.

The adrenal cortex tadpoles were somewhat faster in development and grew better than the adrenal medulla ones. The former budded hind legs on the 71st and the latter on the 81st day. At the conclusion of the experiment the adrenal cortex ones had strong well developed legs, while the legs of the medulla-fed individuals were still short and drawn close to the body.

In previous experiments, in which adrenal cortex and medulla had not been given separately, it was seen that the adrenal-fed tadpoles became extremely light in color after 3 or 4 weeks of feeding. The pigment cells were found to be completely contracted. The suggestion was made "that the extract from the chromaffine cells of the medulla which dissolved in the water caused the pigment cells to contract" and "former experiments with adrenalin would warrant such a suggestion." In the present experiments, however, separate sets of tadpoles were fed on cortex and medulla respectively. After 5 weeks' feeding those fed on adrenal cortex became much lighter than those fed on adrenal medulla or any other food. This difference in color became more evident as the experiment proceeded, until the cortex-fed tadpoles had an extremely light, greenish-yellow tint. Thus the above suggestion is doubtless incorrect, at least in these experiments, yet the true cause of the light pigmentation is still obscure.

These cortex-fed tadpoles also differed from the other groups in still another feature, namely, the peculiar triangular shape (fig. $7 b$ ) of their bodies described above. A few of the brain-fed tadpoles somewhat approached this condition.

The chief purpose of feeding the set I on different foods was to study the influence of the thyroid treatment, after the ani- 
mals had fed for sometime on various other tissues. The tadpoles were about 10 weeks old, when the thyroid was given. They were fed only four times. This feeding caused the same acceleration in differentiation that was noticed in former experiments. Within 3 to 7 days the reaction to the treatment became evident.

There were differences in the rapidity of this reaction among the different sets of tadpoles, as may be seen from the diary, but whether or not these differences are significant as to the value of the food given before the thyroid treatment, remains an open question.

The liver-thyroid-fed tadpoles (fig. $1 \mathrm{k}$ ) were the first ones to develop hind and fore legs. This fact might easily be explained on the ground that the liver-fed group was the most advanced in the entire series (May 8, June 1, June 12, and June 23, in the diary). Yet why those fed, for instance, on spleen, the slowest lot in the series, having no legs even on July 19, and those fed on adrenal medulla which were at the start of the thyroid treatment smaller than the liver-fed ones, should react to the thyroid stimulus as fast as the liver group, cannot be explained on the above basis suggested for the liver-fed group.

On the other hand, the adrenal cortex group though of about the same size are 10 days ahead of the adrenal medulla group in differentiation. Yet after thyroid application they do not react with as great speed as the latter, and fall behind in the series.

Throughout the experiment it was observed that muscle-liverand spleen-fed tadpoles belonged to one class as far as their growth was concerned, while those fed on adrenal cortex, adrenal medulla and ovary formed another class. As soon, however, as the thyroid factor was introduced this classification was disturbed. Thus the previous feeding may influence to some degree the mode of reaction to the thyroid stimulus. No variety of previous feeding can, however, completely prevent this reaction for any length of time. After a shorter or longer interval (in this experiment the difference was only from 3 to 7 days) every tadpole, as far as macroscopic features are concerned, will respond to the thyroid stimulus, no matter what kind of food had been previously given. 
To show the different degrees of response to the thyroid food in the various groups, table 2 may be added. While it does not reveal, as said before, any important points as to the respective value of the different foods given before the thyroid diet, it shows some striking changes in the subsequent positions in the series of the various groups, especially those fed on adrenal medulla, spleen and adrenal cortex.

\begin{tabular}{|c|c|c|c|}
\hline $\begin{array}{c}\text { AVERAGE SIZE AT THE } \\
\text { SIART OF } \\
\text { THE. THYROID DIET }\end{array}$ & $\begin{array}{l}\text { AVERAGE SIZE } \\
7 \text { DAYSLATER }\end{array}$ & $\begin{array}{l}\text { PERCENTAGE LOSS } \\
\text { IN LENGTH }\end{array}$ & TIME OF REACTION \\
\hline muscle & muscle & adr. med, 12.761 & liver (fig. $1 k$ ) \\
\hline liver & liver & liver, & adr. med. (fig. $1 u, 1 d$ \\
\hline spleen & adrenal med. & 15.053 & muscle (fig. $1 o, 1 z a$ ) \\
\hline adrenal cortex & brain & muscle, & spleen (fig. $1 m, 1 z$ ) \\
\hline adrenal medulla & ovary & ovary, & adr. cor. (fig. $1 s, 1 z c$ ) \\
\hline brain & spleen & adr. cor., 28.421 & brain (fig. $1 w, 1 z e$ ) \\
\hline ovary & adrenal cortex & spleen, & ovary (fig. $1 q, 1 z b$ ) \\
\hline
\end{tabular}

\section{Experiment II}

Rana temporaria, Set IV. Figures 4, $a$ to $p$. The tadpoles hatched on April 5 to 6, and the feedings began April 13, 1912. Original length of the specimens was 12 to $12.5 \mathrm{~mm}$.

The diary records of the experiment are given below:

April 13 The feeding was started.

April 16 Those fed on thymus and spleen have become larger than the others.

April 17 Thyroid-fed tadpoles have become considerably smaller than thymus-fed ones and the thymus ones are getting dark.

April 18 Thymus-fed tadpoles are much darker than the others, spieenfed specimens are also getting dark. Thyroid ones now show frog-like bodies.

April 19 Thymus-fed individuals are almost black, spleen-fed very dark, muscle-fed much lighter, thyroid-fed darker than muscle, but lighter than thymus and spleen. Thyroid ones have distinct frog shape, their hind legs are beginning to bud (14 days old).

One set of thymus-fed individuals is now changed to a thyroid diet, thymus-thyroid I.

April 20 The resorption of the tail in thyroid-fed individuals is distinctly noticeable. The specimens all lie on the bottom of the dish and appear frail, taking no more food, while the others in the experiment swim actively. 


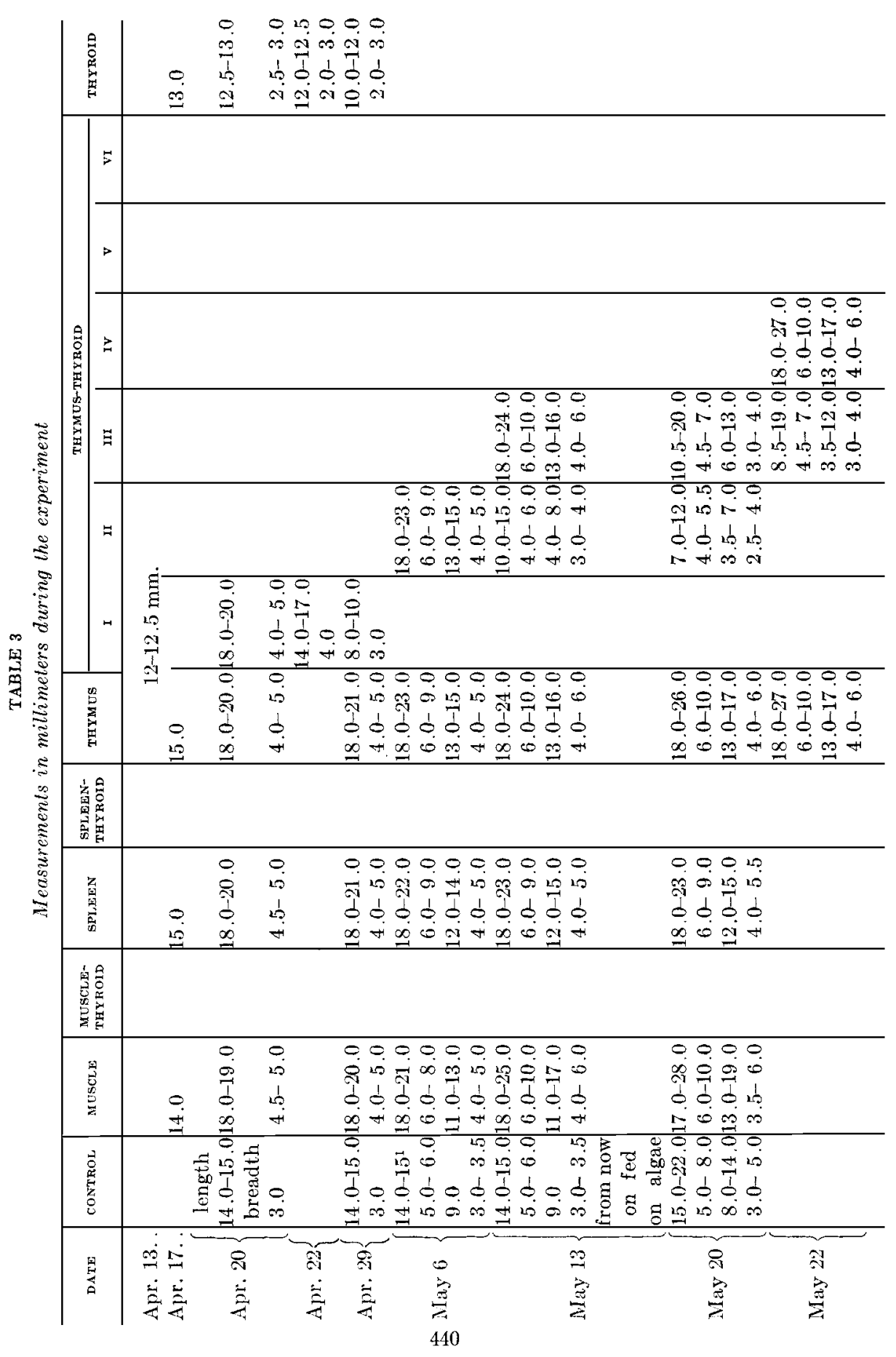




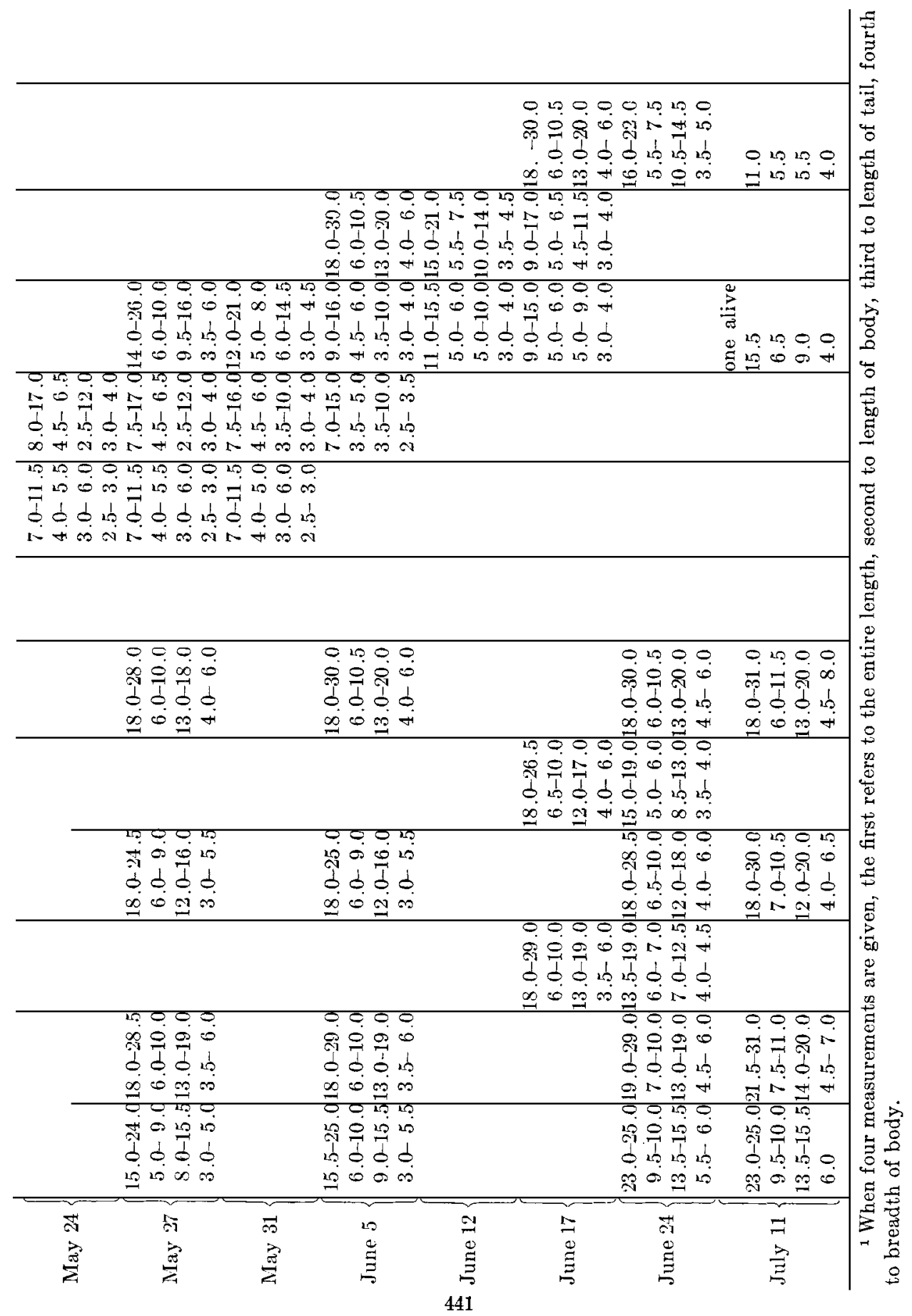


April 21 The thyroid individuals are budding fore legs, the left one first: ${ }^{1} 16$ days old.

April 22 Thyroid ones begin to die.

Only 3 days after the thymus-fed ones were changed to thyroid the influence is noticeable. They have become reduced in size, take on frog shape and bud hind legs.

April 23 Fore legs budding after a treatment of only four days. Thymus-thyroid I do not seem as frail as animals fed on thyroid alone.

April 25 Thyroid-fed animals do not develop their limbs any further, nor do they reduce their tails much further since last observed; progress has ceased.

April 29 The last thyroid and thymus-thyroid I fed animals die.

May 6 A second group of thymus-fed animals is changed to thyroid, thymus-thyroid II.

May 9 Thymus-thyroid II have hind legs appearing and the frog shape is noticeable.

May 10 Thymus-thyroid II have fore legs budding out, the left one first.

May 13 A third group of thymus-fed animals is changed to thyroid, thymus-thyroid III.

May 15 The control animals have not been fed so far. They do not show any sign of differentiation and very little growth. From now they are fed on Elodea canadensis.

May 18 All thymus-thyroid II have both fore legs.

Thymus-thyroid III have hind leg buds.

May 22 All thymus-thyroid III have their hind legs well developed.

Other thymus-fed animals changed to thyroid, thymus-thyroid IV.

May 28 Thymus-thyroid III have fore legs.

Thymus-thyroid IV have hind legs.

June 2 Thymus-thyroid IV have fore legs.

June 5 Thymus-thyroid II begin to die.

June 6 Some muscle-fed tadpoles have hind legs beginning.

June 7 Another group of thymus-fed animals put on a thyroid diet, thymus-thyroid V.

June 12 Thymus-thyroid $V$ have hind legs beginning and the frog shape faintly noticeable.

June 17 Again a group of thymus-fed tadpoles changed to thyroid diet, thymus-thyroid VI.

Part of muscle and spleen fed animals put on a thyroid diet, muscle-thyroid and spleen-thyroid.

June 18 Last thymus-thyroid II dies.

The members of the thymus-thyroid V group have fore leg buds.

${ }^{1}$ Barfurth states that in $80 \%$ of the tadpoles the right fore leg appears first. I have always observed the opposite. 
June 19 All thymus-thyroid V die, thyroid had been. placed in the water every day.

June 20 Thymus-thyroid VI have hind leg buds.

June 21 Muscle-thyroid have hind leg buds.

June 24 Spleen-thyroid have hind leg buds.

June 25 Thymus-thyroid VI and muscle-thyroid groups have fore leg buds.

June 26 Spleen-fed tadpoles have hind legs.

June 27 Spleen-thyroid group have beginning fore legs.

June 8 Thymus group have hind leg buds.

June 29 Control tadpoles have hind leg buds.

July 3 Last animal of the thymus-thyroid III group dies.

July 6 Last individuals of the muscle-thyroid and spleen-thyroid animals are preserved.

July 10 The remaining thymus-thyroid VI are preserver.

July 14 Last one of the thymus-thyroid IV group dies.

July 20 The experiment is discontinued.

The muscle-fed tadpoles are best differentiated.

Since Experiment III was performed along the same lines as Experiment II, it may be well now to give the data of Experiment III and discuss the two groups together.

\section{Experiment IIII}

Rana temporaria, Set III. Figure $3, a$ to $n$. Contained apparently three lots of eggs mixed; they hatched April 7 to 8 and the feedings began April 13,1912. The original lengths of the tadpoles were from 10 to $11.5 \mathrm{~mm}$.

The experimental data are as follows:

April 13 Food is placed in the dishes for the first time.

April 15 Food is first taken by the animals.

April 18 Thymus-fed specimens become darker in color.

April 20 some of the muscle- and thymus-fed tadpoles show hind leg buds.

May 6 Part of the thymus-fed animals changed to thyroid diet, thymus-thyroid I.

May 10 All individuals of the thymus-thyroid I group have hind legs and the frog shape is noticeable.

May 13 Thymus-thyroid I group have fore legs budding, the left one first. They lie on their backs and breathe rapidly.

A second group of thymus-fed animals is put on thyroid, thymus-thyroid II.

May 15 The control has not yet been fed. It remains far behind the other groups in size and shows no signs of differentiation. From now on the control group is fed on Elodea canadensis. 


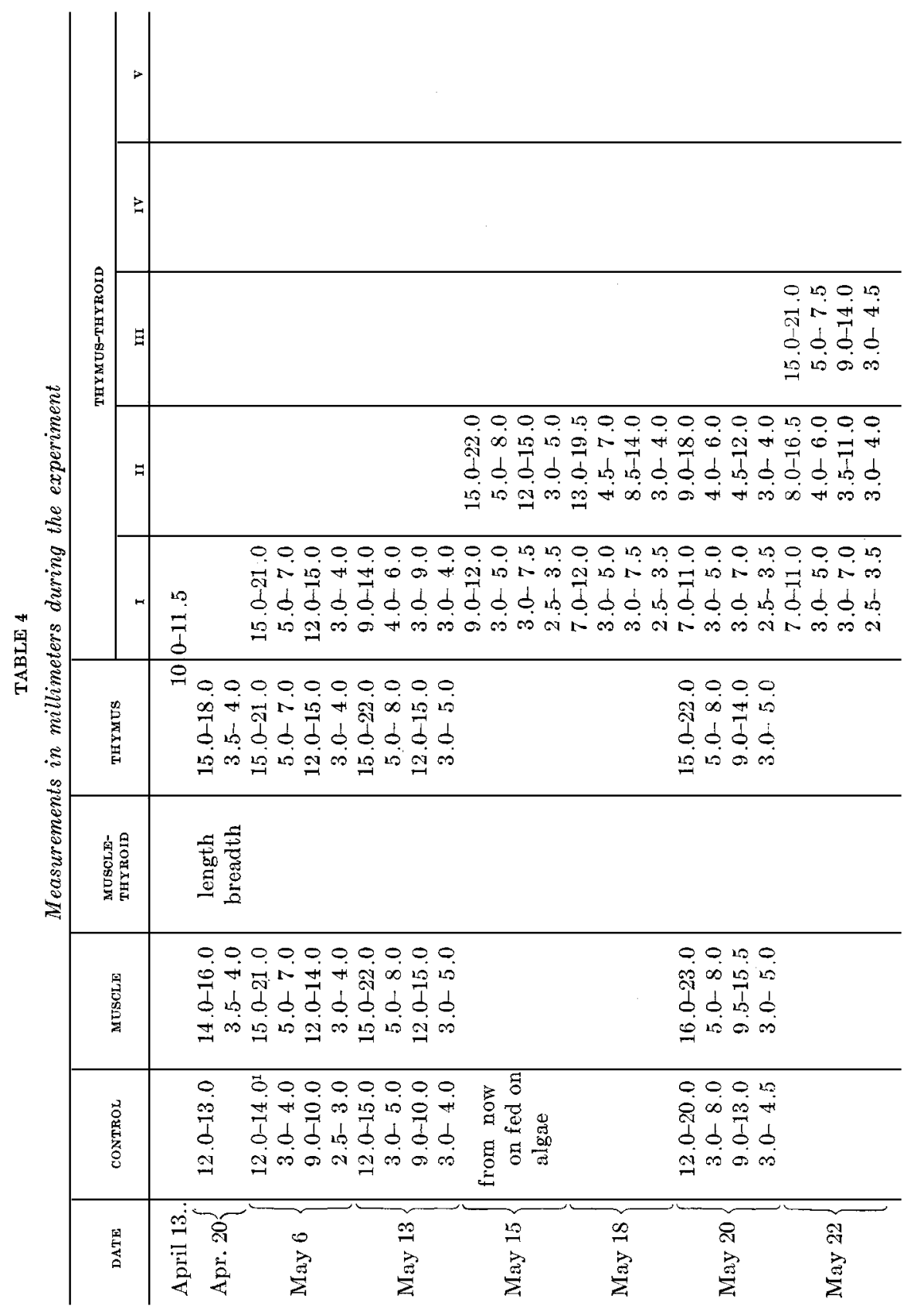




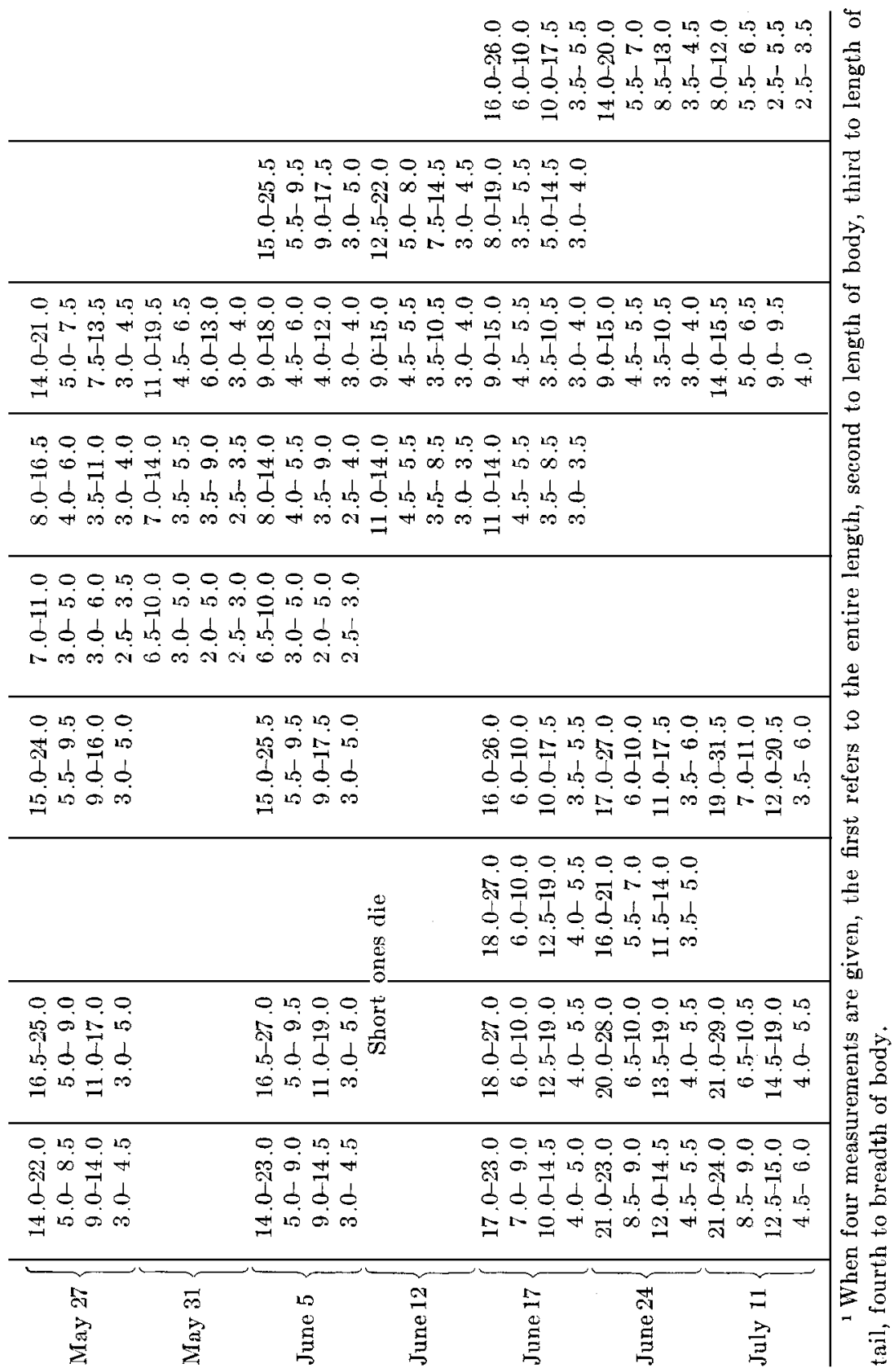


May 18 The thymus-thyroid I animals are hardly able to swim; when disturbed they move for a few seconds with convulsive jerks, then drop again to the bottom of the dish.

May 19 The thymus-thyroid II group (fed thyroid three times only, May 13, 14 and 17) have hind legs and the frog shape becomes noticeable.

May 22 A third group of thymus-fed animals put on thyroid, thymusthyroid III.

May 27 Thymus-thyroid II have fore leg buds.

May 28 Thymus-thyroid III (fed four times on thyroid, May 22, 23, 25 and 26) have hind leg buds.

June 2 Thymus-thyroid III have fore leg buds.

June 7 A fourth group of the thymus-fed tadpoles are put on thyroid, thymus-thyroid IV.

June 9 The last specimens of the thymus-thyroid I group are dying.

June 12 The thymus-thyroid IV animals have hind leg buds and the frog-shape is noticeable.

June 17 A fifth group of the thymus fed animals is changed to a thyroid diet, thymus-thyroid $V$.

Also some of the muscle-fed ones are put on thyroid.

June 18 The thymus-thyroid IV animals have fore legs, but these specimens are dying.

June 20 Last of the thymus-thyroid II are dying.

June 21 Thymus-thyroid $\mathrm{V}$ have hind legs.

June 25 Thymus-thyroid IV have fore legs.

June 26 The muscle-thyroid animals have hind legs.

June 30 The muscle-thyroid animals have fore legs.

July 1 A group of thymus-fed specimens put on a liver diet.

July 4 Some of the thymus-thyroid III group that have been kept on vegetable food since June 5 seem to recover from the thyroid influence.

July 7 The last thymus-thyroid V are dying.

July 14 Muscle-fed tadpoles grow hind legs.

July 20 The experiment is discontinued, and only the muscle-fed animals have extremities.

Experiments II and III were performed for the purpose of determining whether tadpoles of different ages would react to the thyroid diet in similar or different ways. For this purpose a great number of tadpoles were kept on a thymus diet and groups of these were changed to a thyroid diet at various times. Table 5 shows the time of reaction to the thyroid stimulus in the different groups. The number of days in the first columns indicates the respective ages of the animals at the start of the thyroid feed- 
TABLE 5

\begin{tabular}{|c|c|c|c|}
\hline \multicolumn{2}{|c|}{ SET IV } & \multicolumn{2}{|c|}{ SET III } \\
\hline 14 days & $\begin{array}{l}\text { hind } 3 \text { days } \\
\text { fore } 4 \text { days }\end{array}$ & & \\
\hline 30 days & $\begin{array}{l}\text { hind } 4 \text { days } \\
\text { fore } 6 \text { days }\end{array}$ & 28 days & $\begin{array}{l}\text { hind } 4 \text { days } \\
\text { fore } 7 \text { days }\end{array}$ \\
\hline 37 days & $\begin{array}{l}\text { hind } 6 \text { days } \\
\text { fore } 15 \text { days }\end{array}$ & 35 days & $\begin{array}{l}\text { hind } 6 \text { days } \\
\text { fore } 14 \text { days }\end{array}$ \\
\hline 46 days & $\begin{array}{l}\text { hind } 6 \text { days } \\
\text { fore } 11 \text { days }\end{array}$ & 44 days & $\begin{array}{l}\text { hind } 6 \text { days } \\
\text { fore } 10 \text { days }\end{array}$ \\
\hline 62 days & $\begin{array}{l}\text { hind } 5 \text { days } \\
\text { fore } 11 \text { days }\end{array}$ & 60 days & $\begin{array}{l}\text { hind } 5 \text { days } \\
\text { fore } 11 \text { days }\end{array}$ \\
\hline 72 days & $\begin{array}{l}\text { hind } 3 \text { days } \\
\text { fore } 8 \text { days }\end{array}$ & 70 days & $\begin{array}{l}\text { hind } 4 \text { days } \\
\text { fore } 8 \text { days }\end{array}$ \\
\hline
\end{tabular}

ings. The figures in the other columns give the number of days required by each set in developing hind and fore legs.

The similarity of the results in the two series is striking. There is a gradual decrease in the rapidity of action of the thyroid influence up to the age of about 5 weeks followed by a steady increase after this time. Whether or not this is a general rule must be decided by further experiments. It is also difficult to give a satisfactory explanation for this phenomenon, yet the following suggestion may be advanced. The young tadpoles were very quickly affected by the thyroid feedings because the previous thymus diet had not acted long enough to delay or counterbalance the thyroid stimulus. Older animals had enough thymus agens accumulated to retard the thyroid action. Still older tadpoles were more nearly approaching the normal time of metamorphosis and may thus have been ripe to respond to an accelerating stimulus. The last argument, however, seems especially weak, since it introduces a new factor in the action of thymus diet; namely, that if it is prolonged, it loses the retarding influence and thus is less able to counteract the thyroid. This factor ha's not yet been demonstrated; thus no conclusions as to the rapidity of the thyroid influence on different age tadpoles can be based upon it. 
It has been shown, however, in the experiments of 1911 that thymus will affect older tadpoles less than younger ones. Another point may also be mentioned without attempting to explain the situation. Table 6 shows that old thymus-fed tadpoles, when put on a thyroid diet, respond more quickly to the thyroid stimulus than do tadpoles of the same age which have been fed on other substances. One should have expected just the contrary, judging especially from Experiment VI in 1911, in which liverthyroid-fed tadpoles developed their fore legs 3 days earlier than thymus-thyroid-fed ones.

TABLE 6

\begin{tabular}{|c|c|c|c|c|c|}
\hline & \multicolumn{3}{|c|}{ SET IV: 72 DAYS OLD } & \multicolumn{2}{|c|}{ SET III: 70 DAYS OLD } \\
\hline & $\begin{array}{l}\text { Thymus- } \\
\text { thyroid }\end{array}$ & $\begin{array}{l}\text { Muscle- } \\
\text { thyroid }\end{array}$ & $\begin{array}{l}\text { Spleen- } \\
\text { thyroid }\end{array}$ & $\begin{array}{c}\text { Thymus- } \\
\text { thyroid }\end{array}$ & $\begin{array}{l}\text { Muscle } \\
\text { thyroid }\end{array}$ \\
\hline Hind legs in & 3 days & 4 days & 7 days & 4 days & 9 days \\
\hline Fore legs in & 8 days & 8 days & 10 days & 8 days & 13 days \\
\hline
\end{tabular}

In Experiments II and III those tadpoles (fig. $3 c$ to $h, 3 k, 3 m$, $3 n$; fig. $4 e$ to $i, 4 l, 4 n$ to $p$ ) that were transferred from thymus to thyroid diets were fed on the latter gland only three or four times. When they had developed their fore legs water-plants were placed in the dishes. It had been noticed that thyroid-fed tadpoles would die very soon after putting out fore legs. In these experiments those that were placed in dishes containing plants, although they were never seen to feed on the plants, could be kept alive for some time, 20 to 53 days, while those specimens remaining in water in which thyroid was placed longer than was absolutely necessary for developing the extremities died within 10 to 12 days after the beginning of the thyroid diet. Those living longer did not develop any further than those dying early, but remained stationary except for a further reduction in size, especially of the tail.

Table 7 gives the length of time that the different thymusthyroid-fed sets were kept alive in the two experiments. Tadpoles in Experiment III were about 2 days younger than those in Experiment IV, when the feeding began. 
TABLE 7

\begin{tabular}{c|l|c|c}
\hline \multicolumn{2}{c}{ sET Is } \\
\hline $\begin{array}{c}\text { Age at the time } \\
\text { thyroid was given }\end{array}$ & $\begin{array}{c}\text { Days living after thyroid } \\
\text { treatment }\end{array}$ & $\begin{array}{c}\text { Age at the time thyroid } \\
\text { was given }\end{array}$ & $\begin{array}{c}\text { Days living after } \\
\text { thyroid treatment }\end{array}$ \\
\hline 14 days & 10 days (no plants) & & \\
30 days & 43 days & 35 days & 33 days \\
37 days & 51 days & 44 days & 38 days \\
46 days & 53 days days \\
62 days & 12 days (no plants) & 60 days & 11 days (no plants) \\
72 days & 33 days & 70 days & 20 days \\
\hline
\end{tabular}

A glance at table 5 will show that the tadpoles of 37 and 46 (or 35 and 44) days showed the slowest reaction to the thyroid treatment. The possible reasons for this behavior were discussed above.

\section{Experiment IV}

Rana temporaria, Set II. Figure 2, $a$ to $n$. 960 tadpoles hatched on April 6 to 7, 1912, and fed on muscle until June 3. The experiment started on June 5 .

This experiment confirmed the results of the two previous ones. Tadpoles (fig. 2; $a$ ) which had lived for 50 days on an ordinary meat diet were later affected by the thyroid stimulus as greatly as animals fed only on a thyroid diet. The main object of this experiment, however, was to ascertain how long the thyroid agens had to be applied before results were noticeable, and furthermore, whether or not it would be possible to counteract the thyroid influence after one or more days feeding. A great number of tadpoles were reared on muscle and at the age of 50 days were divided into groups of 80 individuals each. The different groups were then fed on thyroid from 1 to 5 days and after this treatment five of the groups were put on a vegetable diet (Elodea canadensis) (fig. 2, $f$ to $i$ ) and 5 others on muscle diet (fig. 2, $c$ to $e$ ).

One group (fig. $2, b$ ) was allowed to starve to test whether hunger following a long period of feeding (over 6 weeks) would bring about a quicker differentiation.

Still another group (fig. $2, l$ ) was kept in water in which small pieces of thyroid gland were placed, but so arranged that the 


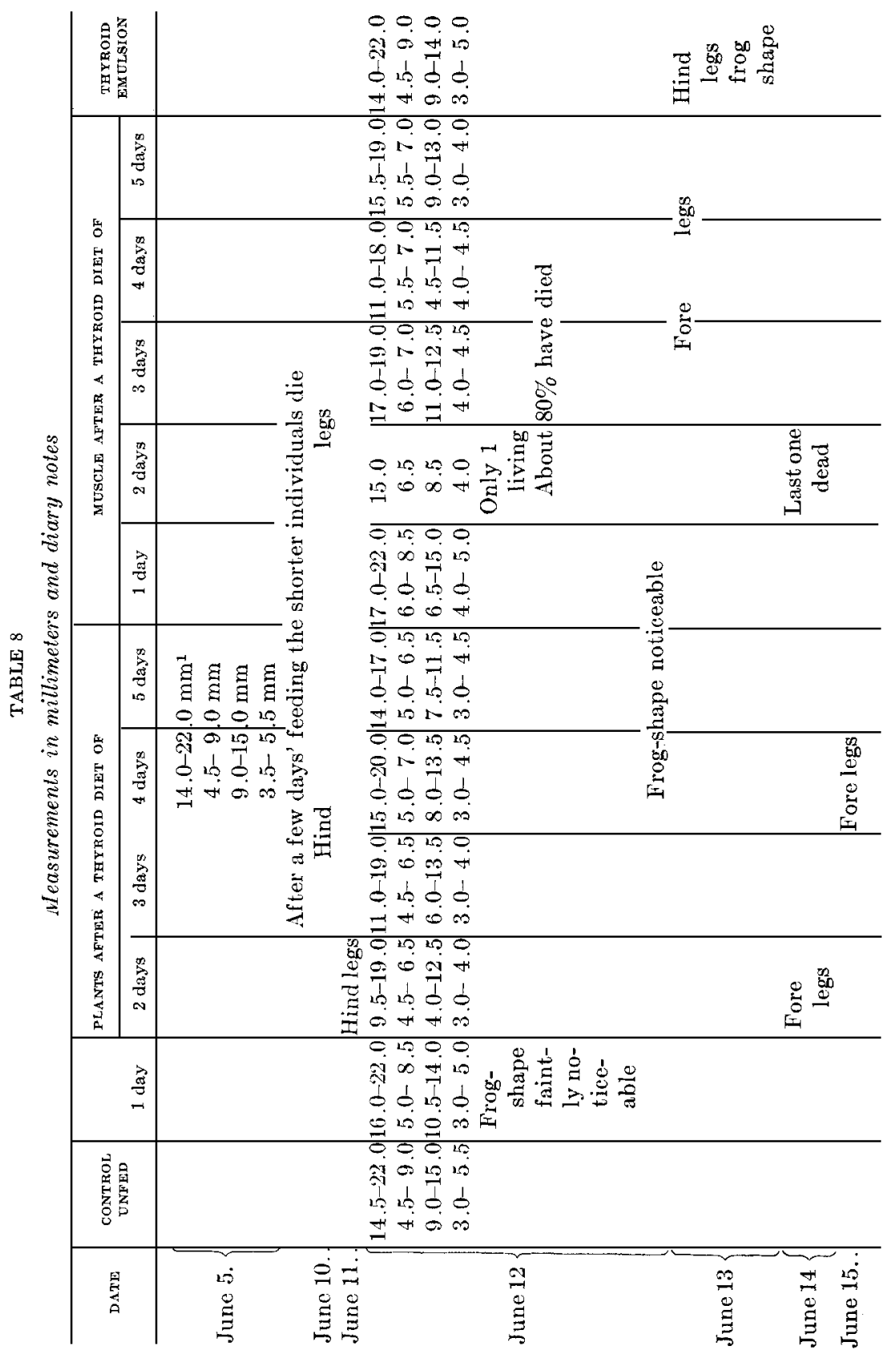




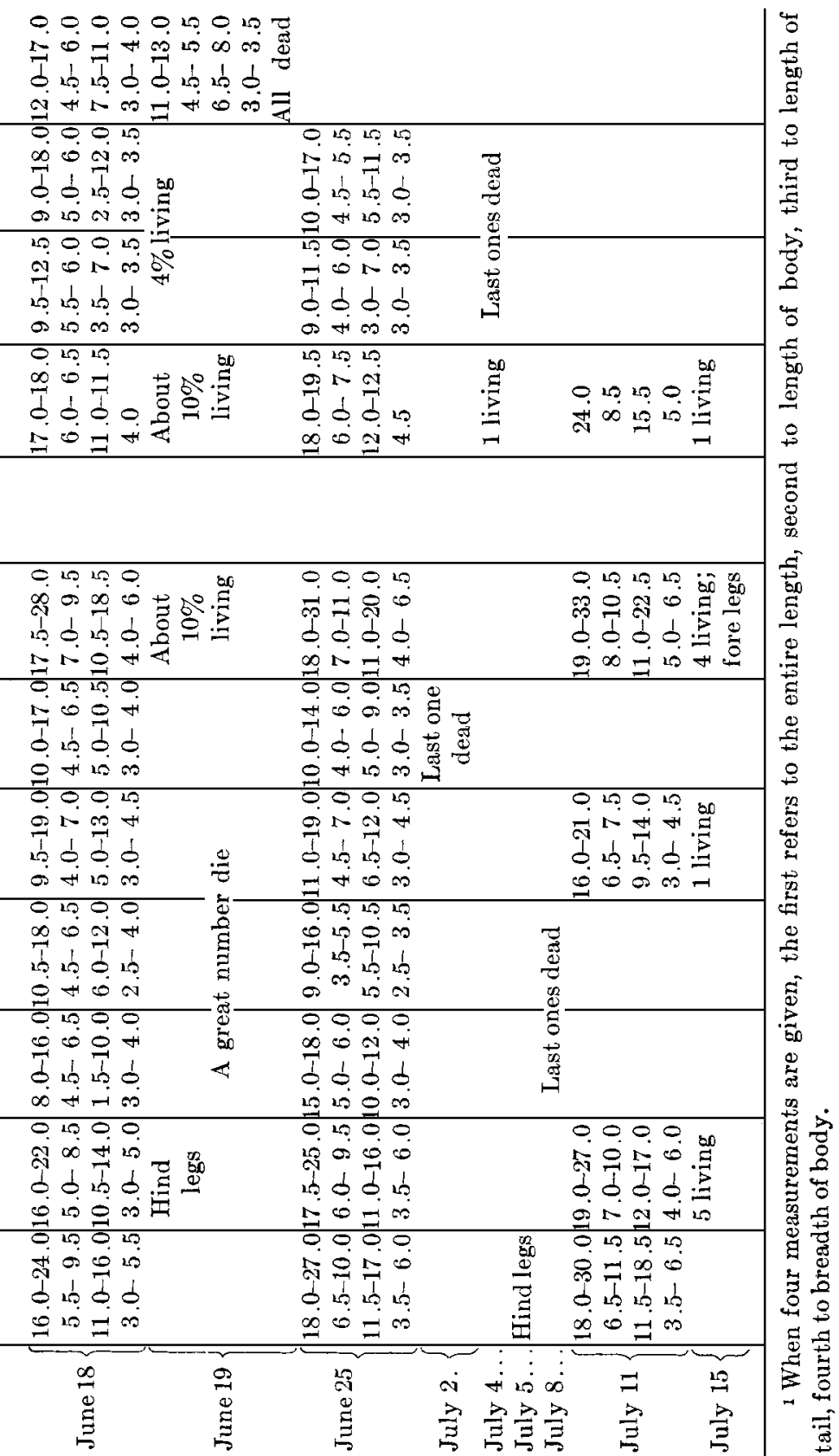


animals could not feed on it. The gland was placed in a small glass vial closed with gauze and allowed to stand upright, the open end being beneath the surface of the water. Thus no thyroid particles could get out into the water, merely an extract or emulsion of thyroid constituents which diffused from the vial into the dish. Animals kept in these dishes developed their hind legs 8 days after the beginning of the experiment and the frog shape became noticeable about the same time. Six days later they all died without having grown fore legs, but their size on that day, June 19, shows that they were completely under the thyroid influence. Therefore the product of the thyroid which caused the rapid differentiation in all the previous experiments must be soluble in water.

The control animals which were kept starving after the 50 days feeding did not grow hind legs until July 5, considerably later than the thyroid treated ones. Thus the results after thyroid application are different from those Barfurth reports in his "Der Hunger als förderndes Prinzip in der Natur," and cannot be attributed to starvation of the tadpoles. Among the ten main groups of the experiment the thyroid influence manifested itself in different ways. As a general result it may be stated that a thyroid application of only 24 hours sufficed to show decided effects (fig. $2 c, 2 f$ ), and that a treatment of more than 24 hours ( 2 to 5 days) gave the typical results described in all previous experiments.

In the five groups that received vegetable food following the thyroid dose and in the five groups that were fed again on muscle, a great number of individuals, 50 to 60 per cent, mainly the shorter ones, died within 2 or 3 days after the first feeding. This accords with observations in other cases where thyroid was given after previous feeding, but is in striking contrast with the happenings in experiments where thyroid food was applied from the start. In the latter experiments very few animals were lost during the first days. It remains to be answered why the application of thyroid should affect tadpoles that had not been previously fed on other diets less harmfully than those previously fed on various tissues. 
The tadpoles which again received muscle after the thyroid treatment reacted more strongly to the stimulus than those put on a vegetable diet. They all grew hind legs within from 1 to 5 days, the frog shape became noticeable very soon, and they died in great numbers, so that 7 days after the beginning of the experiment only 20 per cent were alive. The animals treated from 3 to 5 days grew fore legs on the 8th day, those treated 2 days were all dead on the 9th day; this group was affected most strongly, which may be a mere coincidence. The groups fed only one day grew fore legs on the $42 \mathrm{~d}$ day, at this time only four of this group were alive, only one of the 3 day group, and none of the 4 and 5 day groups, the last ones having died on the 29th day of the experiment. That is, out of 400 individuals only 4 in the 1 day group and 1 in the 3 day group were able to survive the thyroid shock. The table of growth on page 450 shows that these surviving individuals actually begin to grow again. These 4 animals of the 1 day group seem to have absorbed a very small quantity of the thyroid agens. They stop their precocious differentiation very soon and do not grow fore legs until July 17, which is 34 days later than the 3 and 5 day groups.

The second set of tadpoles, those put on a vegetable diet after a thyroid treatment, reacted in a similar fashion to that just described, except perhaps as stated above, they were somewhat less affected. This might suggest that a meat free diet may help to counteract thyroid influences. The 3 and 5 day groups grow hind legs on the 5th day of the experiment, the 2 day group on the 6th day; and the 1 day group not until the 14th day. Fore legs appear in the 3, 4 and 5 day groups on the 10th day, in the 2 day group on the 9th day, in the 1 day group none had appeared on the 46th day, when the experiment was discontinued. While many animals died during the first few days, some were able to keep alive. On the 27 th day the last ones of the 5 day group died, and on the $33 \mathrm{~d}$ day all of the 2 and 3 day groups were dead. There were five of the 1 day group and one of the 4 day group alive on the $42 \mathrm{~d}$ day. These, as the table of growth of page 450 shows, start again to grow. 


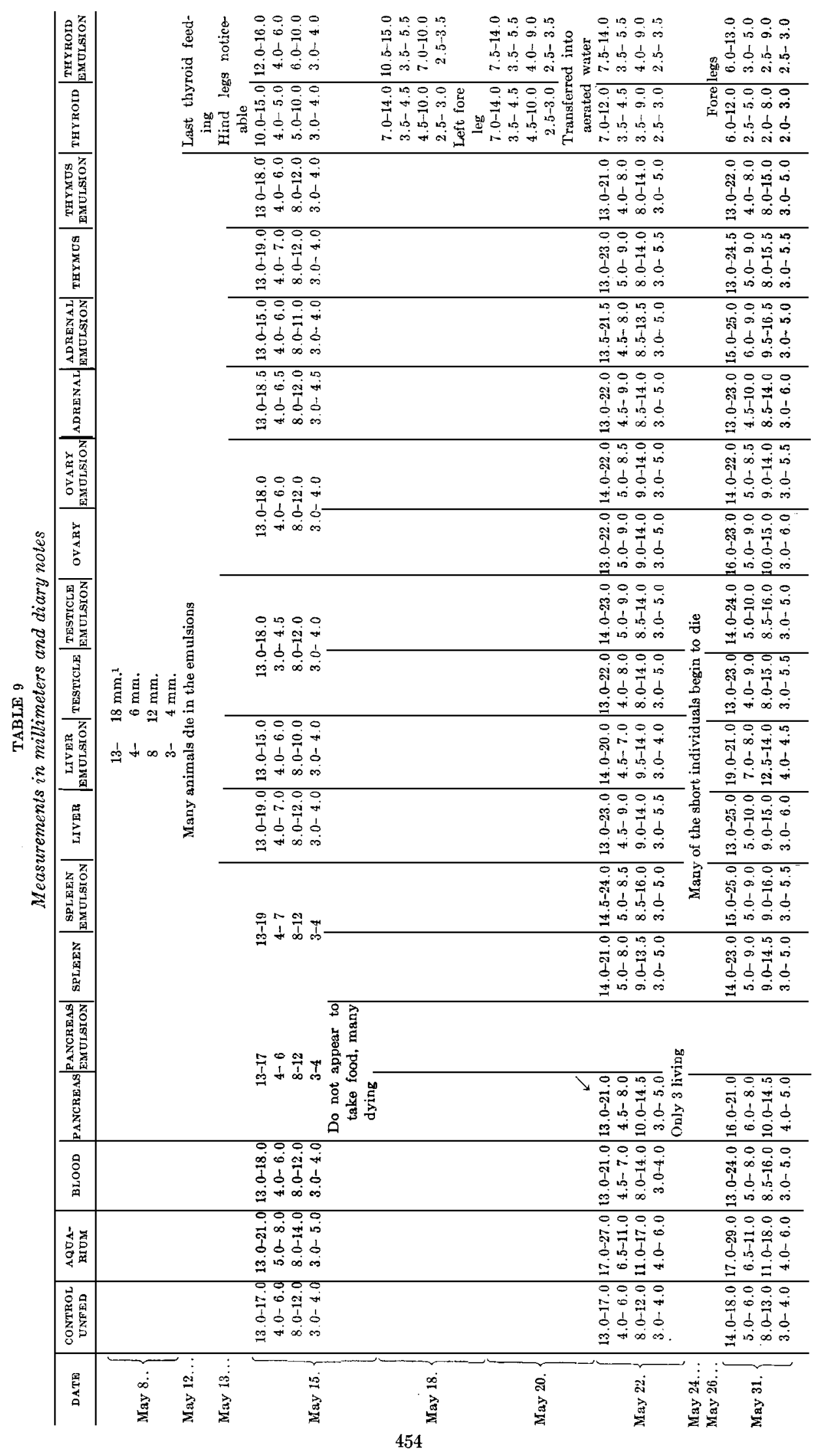




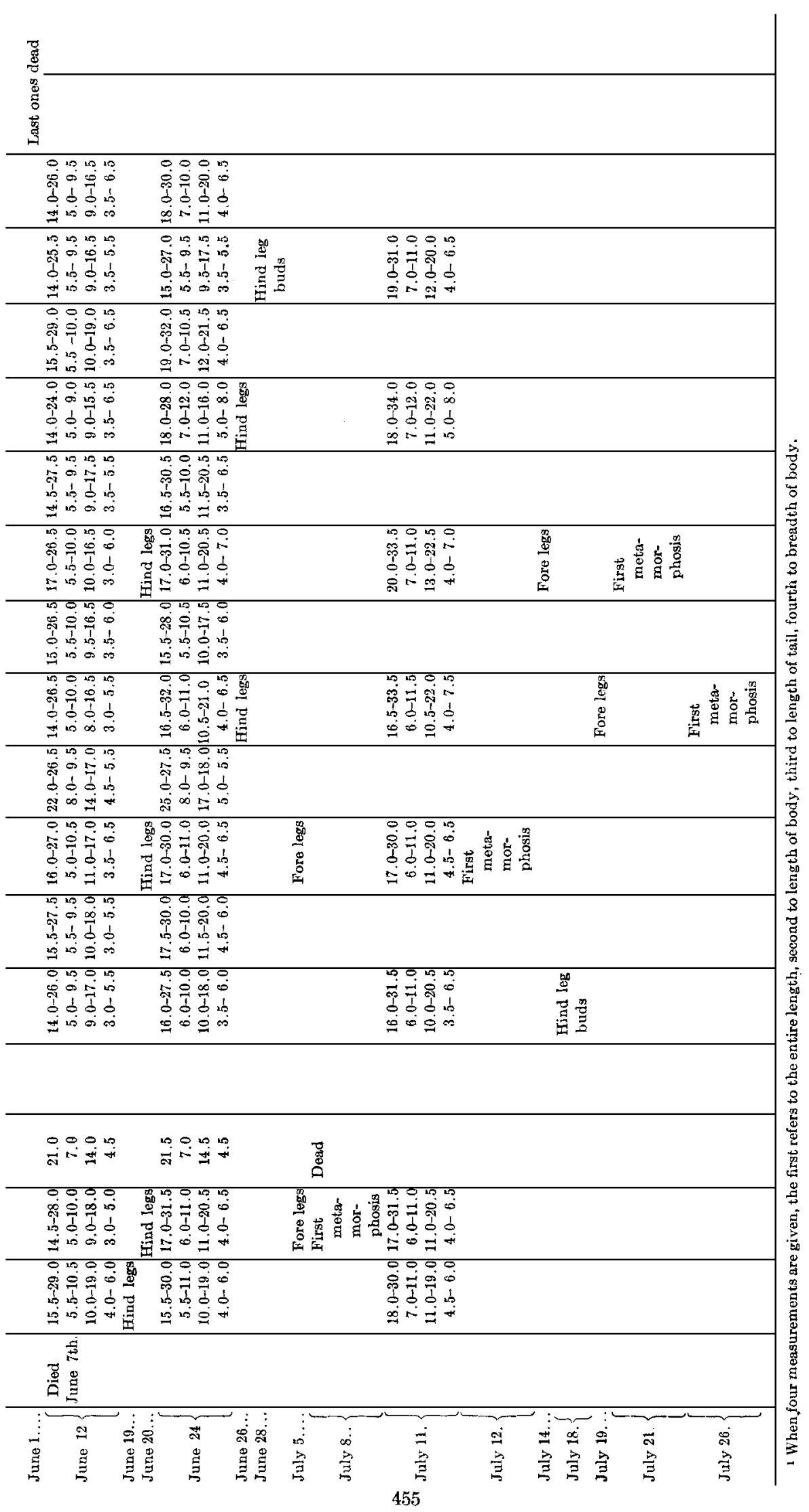




\section{Experiment $V$}

Rana temporaria, Set VIII to XI, voluntarily mixed. These hatched April 10 to 13 and the experiment started May 8, 1912.

In addition to the organs used in the previous experiments, pancreas and testicle were given as food in this experiment. Each organ was given in two forms; with one group of tadpoles a small piece of the tissue was placed in the water; to a second group the food was given in a crushed form, a piece of the tissue being squeezed between the fingers, until it was broken into minute particles. This was done for two reasons. First to allow juices that might form an active part of the glands to ooze out into the water as quickly as possible, second to give the weaker individuals a chance to find food particles. In almost every experiment it was seen that a number of the smallest individuals did not grow and after a time began to die. It seems, however, that this is not due to an inability to obtain food, but because they were less fit to live and were simply weeded out in the early stages of development.

The tadpoles fed on the crushed glands developed in essentially the same manner as the others, thus after several weeks both sets were placed in one dish and fed alike.

One set of animals was fed on clotted blood. They did best of all. A control set was fed on Elodea canadensis and another was starved.

All of the tadpoles were about 4 weeks old at the beginning of the experiment and had not been fed. When starved the animals eat the dead ones, if these are not removed, but their rate of growth can by no means compare with that of tadpoles receiving plenty of food.

The thyroid-fed tadpoles showed the same rapid development as observed in previous experiments. They could not be kept alive longer than 23 days, although after 10 days they were put in water through which a constant current of air was passed. The groups fed on other tissues also showed the usual rate of growth. Those individuals fed on spleen, liver and thymus ran rather parallel courses and progressed somewhat faster during the 
early days of the experiment than the tadpoles fed on testicle, ovary and adrenal. The latter three groups also ran similar courses. The set fed on plants showed a rather rapid growth, about equal to that of the spleen, liver and thymus groups. The tadpoles in these groups reached on the average a length of 30 to $31 \mathrm{~mm}$ at the time of metamorphosis, while the specimens in the slower growing groups reached a length of 33 to $34 \mathrm{~mm}$ before they metamorphosed. This fact might lead one to conclude that the materials fed to the faster groups, vegetable, blood, spleen, liver and thymus, contain an agens which causes a more rapid differentiation than the foods given to the second groups, testicle, ovary, adrenal. This, however, is not the case, since in the first group the spleen- and thymus-fed tadpoles exhibited no signs of an approaching metamorphosis at a time when the tadpoles of the second group had begun to leave the water.

Attention should be called to the fact that in this experiment as in the previous ones of 1912 the spleen- and thymus-fed groups (spleen had not been fed in 1911) showed almost parallel courses of development, neither reaching the stage of metamorphosis when the other groups had. Whether or not this indicates an influence of the spleen, or perhaps of all lymphatic organs, similar to that of the thymus in retarding differentiation I am at present unable to decide.

The tadpoles intended for a pancreas diet did not feed freely and most of them died early.

The starved animals did not differentiate beyond their original stage and began to die about 4 weeks after the beginning of the experiment.

The pigmentation exhibited by the animals was very much the same as in previous experiments. The thymus-fed individuals, however, did not become as dark as usual. Those fed on blood and plants became very dark.

\section{Experiment VI}

Rana temporaria, Set V to VII. Figure $5, a$ to $e$. Probably three sets mixed. They hatched April 6 to 8 and were not fed until May 24 , when the experiment began. 
During the early part of the season hypophysis was not available, so that no experiments with it could be carried out simultaneously with the other. Therefore this late experiment of hypophysis feeding is not of great significance. It is reported here to show the rates of growth of tadpoles fed on glandular and others on the nervous parts of the hypophysis.

TABLE 10

Measurements in millimeters, and diary

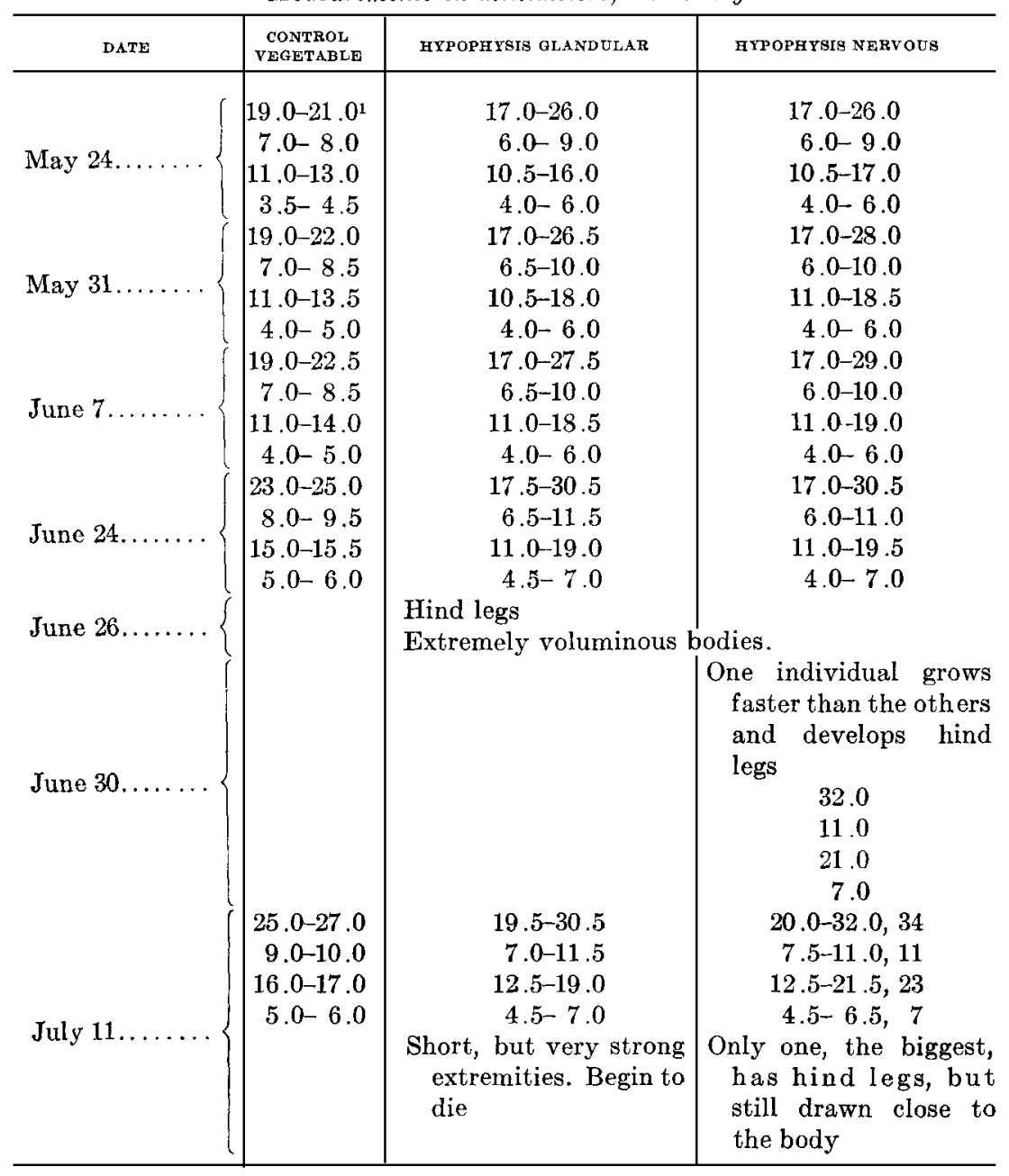

1 When four measurements are given, the first refers to the entire length, second to length of body, third to length of tail, fourth to breadth of body. 
The difference between the rates of growth of the two sets is not marked, there may be a little faster growth in the set fed on neural hypophysis. The tadpoles fed on glandular hypophysis (fig. $5 b, 5 d$ ) show decidedly better differentiation and gradually become less pigmented than those fed on neural hypophysis (fig. $5 e$ ).

\section{Experiment VII}

Bufo vulgaris, Set I. Figure $8, a$ to $d$. Hatched April 10 to 20, 1912, and the feeding began May 6 .

The experimental data are as follows:

May 5 The feeding began.

May 11 All the thyroid-fed specimens have hind legs and the frog shape is noticeable. They were fed only four times.

May 18 Thyroid-fed animals have developed fore legs.

May 22 Algae were placed in with the thyroid-fed tadpoles.

June 18 Last thyroid-fed ones die.

June 20 Thymus-fed ones have hind leg buds.

June 24 Control animals have hind leg buds.

July 11 The muscle-fed tadpoles have the best differentiated hind legs. July 14 Muscle-fed animals grow fore legs.

July 20 The first metamorphosis in muscle-fed group. The control still have very small hind leg buds. Thymus-fed animals have their hind legs still drawn close to the body.

This experiment introduced a new species into the study, Bufo vulgaris, yet the results, as one might have expected, are essentially the same. The thyroid-fed group (fig. 8, $d$ ) showed their usual precocious differentiation, their decrease in size is not as marked as in the Rana species. The thymus-fed group (fig. $8, c$ ) did not grow much faster than the muscle-fed ones (fig. $8, b$ ) and towards the end of the experiment they actually fell behind in size, yet they showed little, if any, differentiation at the time of the first metamorphosis of the muscle-fed tadpoles. A considerable number of the thymus group died when they reached a length of about $21 \mathrm{~mm}$ (status thymicus, thymus death). 
TABLE 11

Measuremenis in millimeters

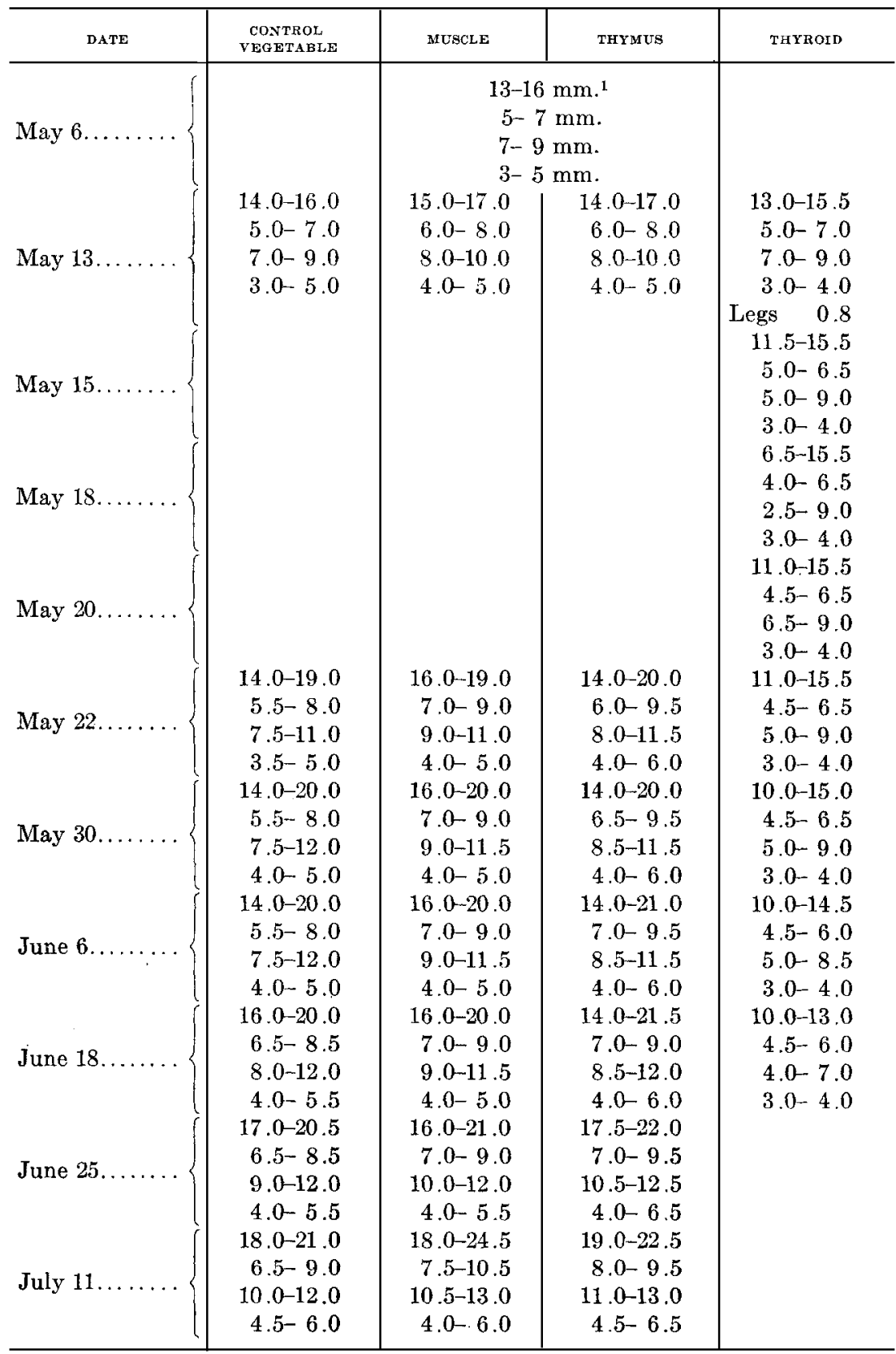

1 When four measurements are given the first refers to the entire length, second to length of body, third to length of tail, fourth to breadth of body. 
The next three experiments to be described were performed for the purpose of studying the influence of a mixed diet on growth and development. One kind of food was given one day and another the next. Previously the animals had been fed for a considerable length of time on one kind of tissue and were then transferred to another.

Experiments VIII and IX consider a thyroid-thymus diet only. The tadpoles of Experiment VIII had been fed on muscle before the thyroid-thymus treatment began, while those of Experiment IX had starved. It may be well at present to record the notes

TABLE 12

Measurements in millimeters and diary notes

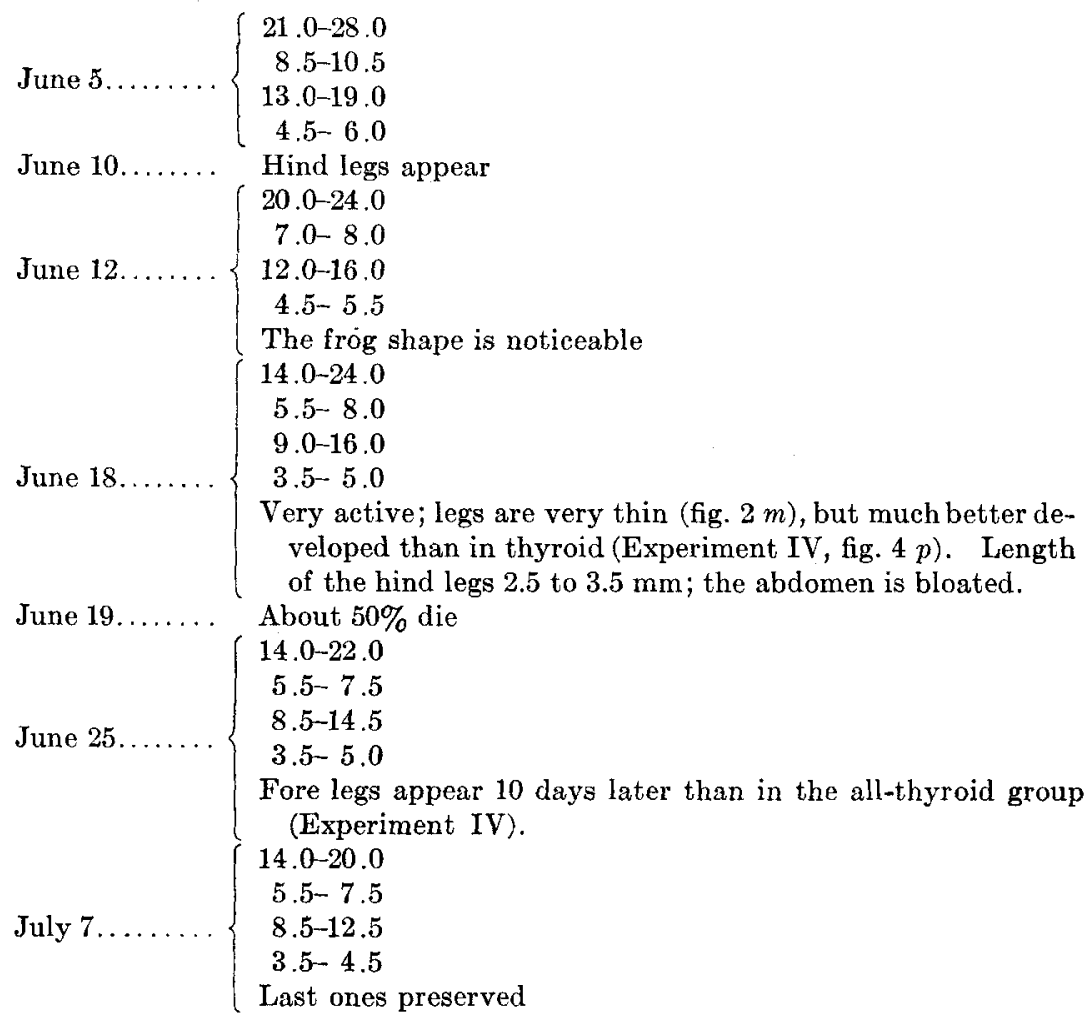


from these experiments and later discuss them in connection with Experiment X, in which several kinds of foods in various combinations were applied.

TABLE 13

Measurements in millimeters and diary notes

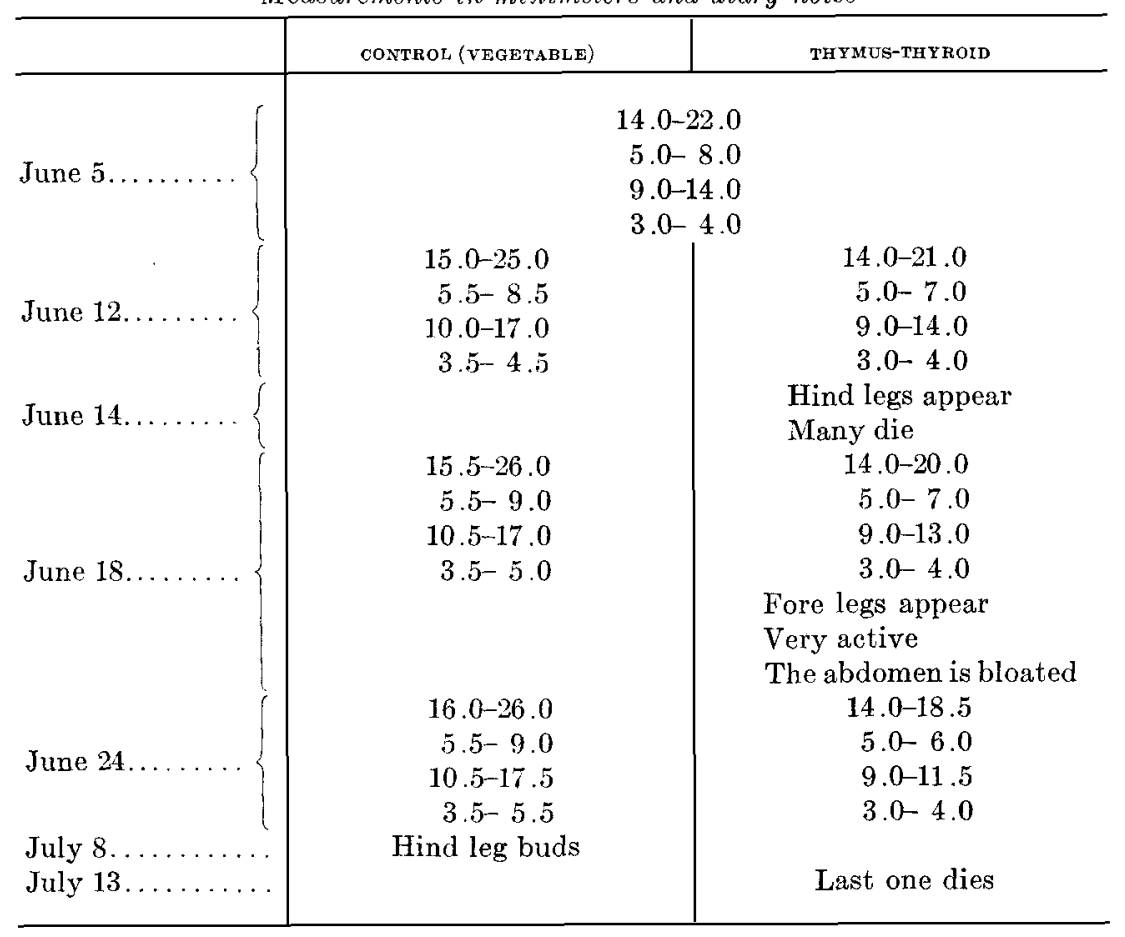

\section{Experiment VIII}

Rana temporaria, Set II. Figure 2, $k, 2, m$. Hatched April 6 to 7, 1912 (Experiment IV), and fed on muscle until June 3. The largest individuals of Set II were selected for this experiment. The feeding of thyroid-thymus began on June 5 .

\section{Experiment $I X$}

Rana temporaria, Sets V to VII. Figure 6, a to $d$. Probably three sets mixed. Hatched April 6 to 8, 1912, and not fed until June 5 , when the experiment was started. 


\section{Experiment $X$}

Bufo vulgaris, Set III. Figure 9, $a$ to $r$. Brought into the laboratory May 21, 1912, size 18 to $23 \mathrm{~mm}$, age unknown. Experiment started June 5. Thirteen groups of tadpoles, 150 individuals in each, were given food as indicated below; one group was starved.

A part of this experiment corresponds to Experiment IV in which several groups of tadpoles of Rana temporaria were fed on thyroid for from 1 to 5 days respectively and afterwards put on a vegetable diet. The Bufo tadpoles reacted very quickly to the thyroid stimulus, but when the thyroid feeding was stopped, they seemed to overcome the thyroid influence more readily than any other tadpoles. The groups fed on thyroid from 3 to 5 days (fig. $9, b$ to $d$ ) developed hind legs 5 days after the first feeding, showing as in other experiments, that a 3 day feeding of thyroid gland suffices to give the typical results. The 2 day group budded the hind extremities on the 7th day and the 1 day group on the 11th day. These intervals approach close to those observed in Experiment IV, which were 5, 6 and 14 days. The anterior extremities appear in the 5 day group 14 days after the first feeding (in Experiment IV on the 10th day) and this group begins to undergo metamorphosis on the 18th day. In the other, 1 to 4 day groups, the after-treatment with vegetable food seems to check the hastened differentiation following the intake of thyroid tissue. They finally do not go much faster than tadpoles which had not received thyroid. It might thus appear as if the Bufo tadpoles had a stronger resistancy against the thyroid stimulus than the Rana larvae. This point is not entirely clear, however, since the former had not received any food before the thyroid feedings began, while the latter had previously lived for $\mathbf{5 0}$ days on muscle. As has been stated above, any meat diet before or after the thyroid treatment is apt to render the animals more susceptible to the thyroid stimulus than does starvation.

The thyroid treated Bufo tadpoles do not reduce their size so much as the Rana tadpoles, as before mentioned under Experiment VII. 


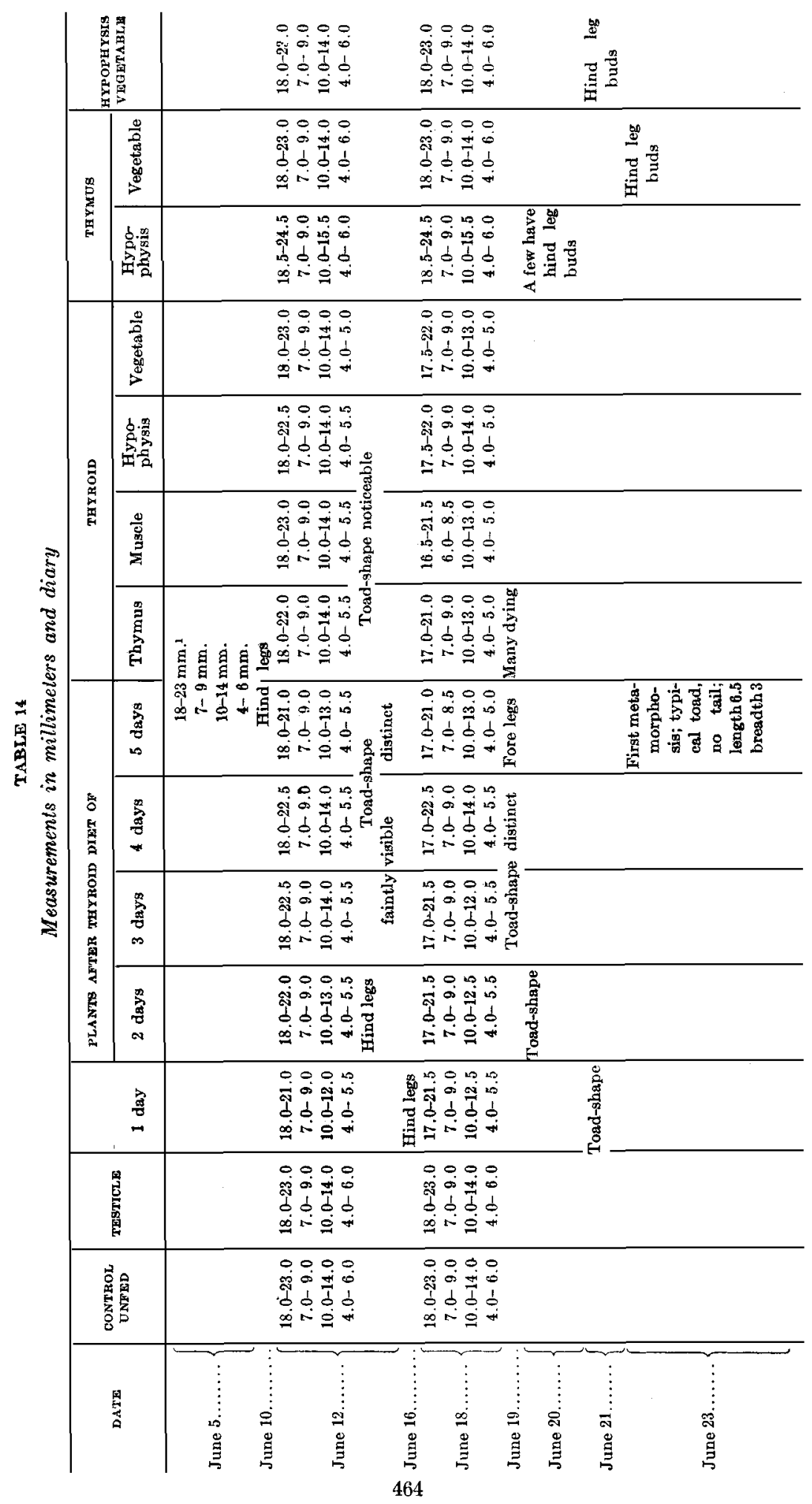




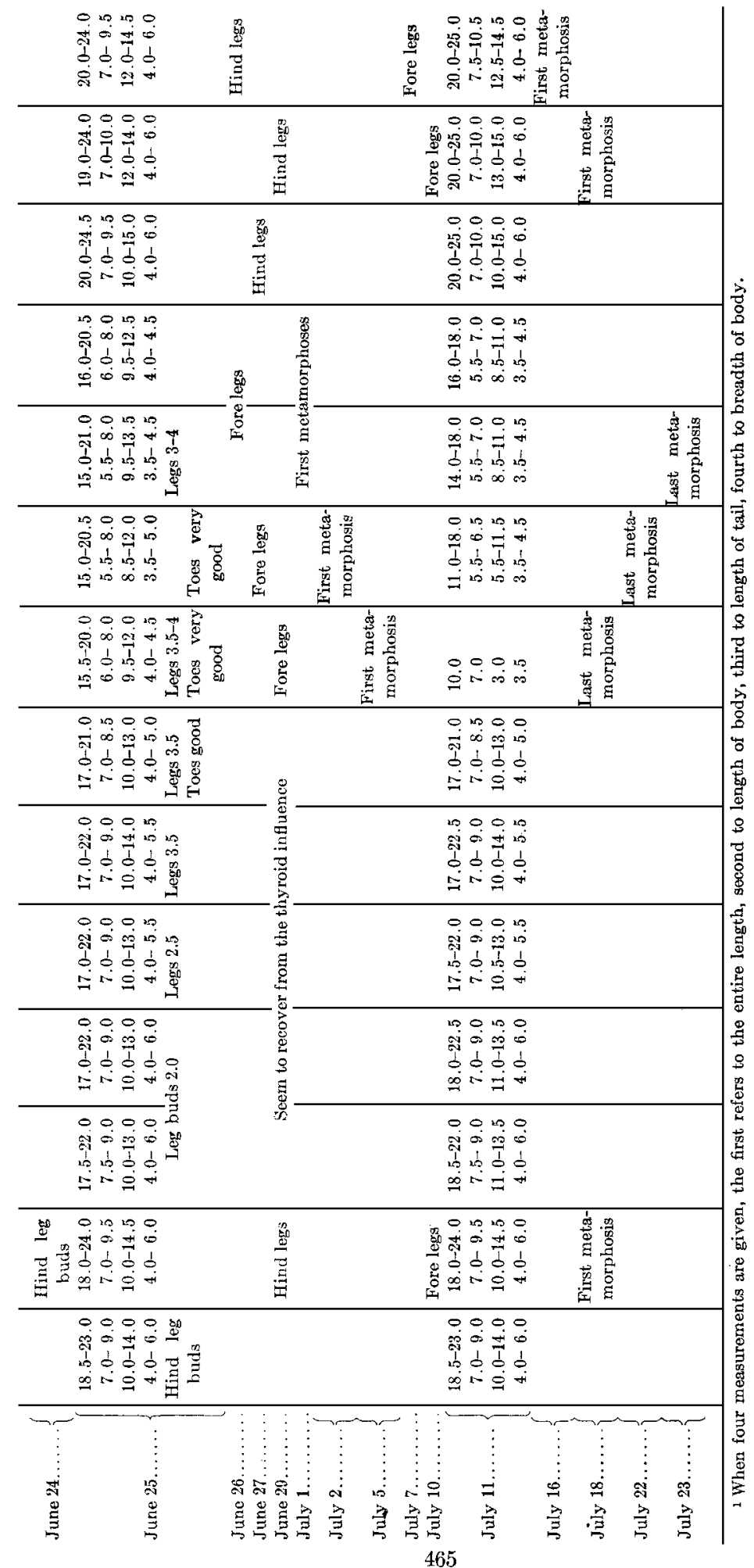


The main interest of Experiment $\mathrm{X}$ lies in the results following the mixed feedings of two kinds of animal tissues or animal tissue and plants.

It will be seen from the notes that, whenever thyroid tissue was one of the two foods it exerted an accelerating influence on development. The four groups fed on thyroid-thymus (fig. $9 h$ ), thyroid-muscle (fig. $9 f, 9 n$ ), thyroid-hypophysis (fig. $9 i, 9 p$ ) and thyroid-plants (fig. $9 g, 9 q$ ) developed their hind legs on the 5 th day. The fore legs appeared in the third and fourth groups on the 21 st day, in the second group on the $22 \mathrm{~d}$ day and in the 1 st group on the 24th day and the tadpoles of the several groups began to metamorphose in the same order. These facts indicate that the thymus was best able to counteract the thyroid, the hypophysis and plants least. It is peculiar, however, that the order of the last individual metamorphoses is exactly the reverse, the thyroid-thymus group completing the change first, the thyroid-plant group last. It is doubtful whether this has any connection with the fact that the greatest reduction in size was in the first group and gradually less down to the fourth.

We may now compare these thyroid-thymus results with those of Experiments VIII and IX. They are essentially alike, the thymus always being able to check the thyroid influence to some degree, but unable to suppress it entirely (fig. $2 k, 2 m, 6 b, 6 d$, $9 h)$.

The remaining three groups, thymus-hypophysis (fig. $9 i, 9 p$ ), thymus-plants (fig. $9 k, 9 q$ ) and hypophysis-plants run much slower than the corresponding thyroid groups. Their hind legs appear from 16 to 19 days later than in the thyroid combination feedings.

The hypophysis-plant group leads the three, the thymus-plant group is a few days behind. This corresponds to the thyroid groups, where the hypophysis was less able to counteract the thyroid acceleration than was the thymus. In the thymus-hypophysis group $(9 l, 9 r)$ two retarding factors combine, therefore the tadpoles fed on this diet never develop fore legs nor do they begin to metamorphose. Yet they are very big healthy specimens. 
It is thus clear that, whenever thyroid forms a part of the diet, a precocious differentiation sets in; when thymus is added (thymus-thyroid, thymus-hypophysis, thymus-plants), the opposite influence is noticed.

One group $(9 \mathrm{~m})$ of Bufo tadpoles was starved to test again whether hunger might cause differentiation, but no differentiation was noted even 5 weeks after the start of the experiment.

Finally another group was fed on testicle. The testicle diet had not been fully tested before. The development of these tadpoles did not differ from the control and this group can therefore serve for a further comparison with the groups given a mixed diet.

Experiments were also begun on Triton alpestris and on Bufo vulgaris tadpoles which had a part of their tails amputated, but the time was too short to carry them out completely.

Feedings were started with Triton alpestris larvae on June 24. On July 12 the outer gills of the thyroid-fed ones had disappeared and the fore legs were well differentiated. The thymus-fed specimens still possessed their outer gills and had only small buds of their fore legs. The animals treated with other foods showed intermediate conditions.

Bufo vulgaris tadpoles of 19 to $23 \mathrm{~mm}$ in length, tails 10 to 14 $\mathrm{mm}$. long, had $5 \mathrm{~mm}$ of their tails amputated on June 24 . The next day separate groups were started on thyroid, thymus, muscle and vegetable diets. The thyroid group developed hind legs on July 3 (8th day) and fore legs on July 12 (17th day). The thymus and muscle groups developed hind legs on July 9 (14th day). Their measurements are given in table 15 , page 468 .

The thymus-fed ones had grown considerably by July 14 and regained their former average length, since they had almost completely regenerated their tails. The other groups had grown and regenerated much less, the thyroid least of all, while in turn it showed the fastest differentiation. These observations correspond with those of 1911. Romeis has studied extensively the 
TABLE 15

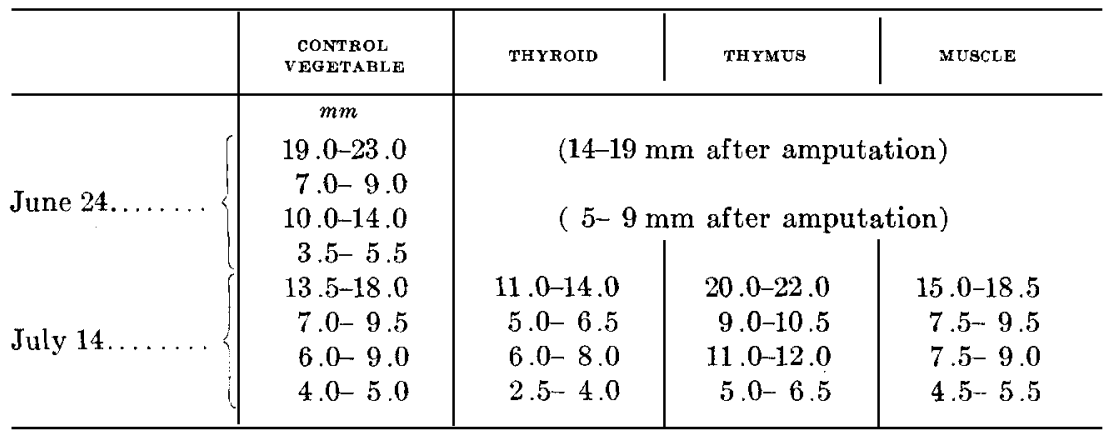

influence of different diets on the regeneration of the tail in Rana esculenta tadpoles.

The experiments of 1911 and 1912 leave no doubt that the mammalian thyroid gland contains an agens which, when the gland is given as food, calls forth a rapid differentiation in a developing vertebrate organism. This differentiation may be brought about at any stage of development, before maturity is reached. The differentiation may therefore be highly precocious in cases where the treatment is begun on extremely young animals. Experiment I showed that tadpoles could be brought to the point of metamorphosis within 18 days after hatching, while normally they would require 10 to 12 weeks to reach such a stage. The results of this premature metamorphosis are perfect frogs of minute size, pygmy frogs, as the figures show (fig. $4 o, 4 p$ and others). The thyroid influence is very decided and there is no escape from it for any tadpole given a thyroid diet. All of the individuals, even if thousands be employed as was the case in several experiments, will react almost immediately to the thyroid stimulus, so that certain changes in their structure may be observed after 24 hours, when only one application of thyroid has been made. They will all react simultaneously so that any individual differences in development will become unobservable.

The experiments further bring out the fact that the time of reaction to the thyroid stimulus varies to a certain degree with the 
kind of food that had been given before the thyroid diet was started. There is also a difference in response between previously starved and fed tadpoles. The experiments with mixed diets showed that the accelerating influence of the thyroid could be checked to some extent and the rapid differentiation more or less retarded. However, there is no complete counteraction against the thyroid stimulus, so that sooner or later any tadpole, receiving-thyroid after other or mixed with other diets, must respond to its influence.

Experiments were carried out to determine the least amount of thyroid food necessary to produce the typical reactions, and also to determine whether or not the tadpoles could recover from the thyroid shock if afterwards put on other food. A feeding of only 24 hours-that is to say, the thyroid was kept in the dish for about 24 hours, though the animals did not feed on it continuously - sufficed to cause a hastened differentiation. A feeding for three days was enough to give the fastest rate of differentiation, a rate that could not be increased by longer feedings.

When thyroid is applied too rapidly, the animals usually die very soon after the appearance of their fore limbs and the simultaneous reduction of their tails. By careful feedings at rather long intervals and in all not more than four times, the animals may be kept alive for several weeks. They will not undergo, however, any further changes, except perhaps a continued reduction of their tails, nor will they ever feed again. In 1911 I succeeded in bringing some tadpoles to a complete absorption of their tails and these thyroid frogs were kept alive on wet sand for from 2 to 4 days. In 1912 some Bufo tadpoles almost completely absorbed their tails under the thyroid treatment (fig. $9 e, 9 n$ ), but could not be kept alive for more than 24 hours.

A recovery from the thyroid influence is extremely rare. Only 5 individuals out of 400 in one experiment and 6 in another were able to survive, and, although, they were never seen to feed, began slowly to grow again after a standstill of several weeks. 
Not one of the many thousand tadpoles fed on thymus in the spring of 1912 could be brought to metamorphosis during the 15 weeks in which the animals were under observation, while tadpoles of the same set, though fed on other substances, metamorphosed before that time (fig. $4 o, p$, liver). In some experiments the thymus fed tadpoles never succeeded in growing their hind extremities before the controls completely metamorphosed. Yet the thymus tadpoles would grow very rapidly, especially during the first weeks of the experiments.

The tadpoles feed on spleen behaved in very much the same way as the thymus-fed ones, though they always were somewhat ahead of the latter and did not counteract the thyroid feedings so strongly. Of the great number of spleen fed tadpoles also not one could be caused to metamorphose.

We must therefore conclude that the thymus and to some extent the spleen also, and probably the lymphatic organs, when given as food, will cause a rapid growth followed by a rather late differentiation or none at all.

These experiments with various foods, except thyroid, thymus and spleen, and the investigations of other workers show that the animals must reach a certain constant minimum size before the final metamorphosis can begin. There is on the other hand a constant assimilation of food and a gradual increase in body size up to a constant maximum, beyond which a normal animal may not pass without the beginning of the final differentiation and metamorphosis.

In the thyroid-fed tadpoles there is differentiation without growth, in the thymus- (and spleen-) fed tadpoles growth without differentiation. The experiments, therefore, emphasize the fact that in development we deal with two entirely separate factors, the factor of growth and the factor of differentiation.

The two naturally work simultaneously; but differentiation is not the result of growth, otherwise there could be no thyroid differ- 
entiation without growth. Nor must growth necessarily be followed by differentiation, as seen in the growing thymus tadpoles.

One might say that ordinary foods which are being assimilated bring with them the two factors of growth and differentiation. Then the assumption is necessary that the thyroid food lacks the power of causing growth, while the thymus and spleen lack the power of causing differentiation. But we can hardly assume that all the various kinds of foods an animal may take in, with the only exceptions of thyroid and thymus, contain these two factors in the proper proportions.

The factors for growth and differentiation can only be located within the organism itself.

We face the following propositions:

1. The thyroid has the power to excite differentiation, but it lacks the power to cause growth.

The thyroid calls forth differentiation, whether the animals be small or large, and without regard to the standard minimum size, necessary for the final change. It must possess an agens for stimulating differentiation which other foods do not possess. That the thyroid also possesses a power which prevents growth is not evident. The suppression of growth may merely be incidental, for rapid differentiation does not allow growth.

2. The thymus has the power to stimulate growth, but lacks the power to excite differentiation.

It has been stated above that tadpoles feeding on any food (except thyroid) reach a maximum size, and when this maximum is reached, differentiation begins independently. The thymus-fed tadpoles reach this maximum size and differentiation should set in of itself, even if the thymus lacked the necessary stimulus. But differentiation does not begin; therefore the thymus (and spleen) must exert an influence not possessed by the other foods which suppresses differentiation. That the thymus possesses the power to stimulate growth, is again not so evident, since the thymus growth may be merely the normal result of the intake of food. The thymus growth is rather rapid, but this may be attributed to the better nutritive qualities of the thymus tissue: The thymusfed tadpoles may also grow beyond the normal as brought out in 
1911, yet this again may be merely incidental. There is no beginning of differentiation in thymus-fed tadpoles which would check a further growth.

We can only say with reasonable safety:

1. The thyroid possesses a quality that stimulates differentiation, not contained in any other food used. ${ }^{2}$

2. The thymus (and spleen) possess a quality that suppresses differentiation not contained in any other food used.

Thus the thyroid and thymus must produce, or at least contain, agents which, when passed into developing organisms, in the one case stimulate, in the other suppress, differentiation. The production of such substances to be thrown into the circulation characterises the thyroid and thymus as glands with a positive internal secretion. That these two types of tissues may also be capable of performing the reverse action, viz. the elimination of certain substances from the circulation, as has been assumed especially for the thyroid, is neither demonstrated nor denied by these experiments.

The other glands used in the studies may or may not contain either the accelerating or the depressing power. However, the macroscopic differences in the rate of growth and differentiation of tadpoles fed on such glands and of the control animals are only slight and might easily be attributed to differences in the nutritive values of the various foods. The feeding experiments on tadpoles are, therefore, not likely to reveal these factors, if at all present in other glands, in a striking degree. Their study must be left to experiments of a different kind.

${ }^{2}$ By 'differentiation' is meant merely the macroscopic changes, hind, forelimbs, metamorphosis. The microscopic differentiation will be discussed in a later paper. 


\section{LITERATURE CITED}

Barfurth, D. 1887 a Versuche über die Verwandlung von Froschlarven. Arch. f. mikr. Anat., Bd. 29, p. 1.

$1887 \mathrm{~b}$ Der Hunger als förderndes Prinzip in der Natur. Arch. f. mikr. Anat., Bd. 29, p. 28.

Basch, K. 1906 Beiträge zur Physiologie und Pathologie der Thymus. Jahrb. f. Kinderheilk., Bd. 64 ; 1908, Bd. 68.

BIEDL, A. 1910 Innere Secretion, I. Auflage. Wien-Berlin. 1913 Innere Secretion, 2. Auflage. Wien-Berlin.

Gudernatsch, J. F. 1912 a Fütterungsversuche an Kaulquappen. Demonstr. Verh. Anat. Ges., Bd. 26. Vers. München.

1912 b Fütterungsversuche an Kaulquappen. Vorl. Mitteil. Centralbl. f. Physiol., Bd. 26, no. 7 .

$1912 \mathrm{c}$ Feeding experiments on tadpoles.I. Arch. f. Entwickel.Mech., Bd. 35, p. 457.

Hammar, I. A. 1910 Fünfzig Jahre Thymusforschung. Ergebn. d. Anat. u. Entwicklungsg., Bd. 19.

LrebeN, S. Über die Wirkung von Extrakten chromaffinen Gewebes (Adrenalin) auf die Pigmentzellen. Centralbl. f. Physiol., Bd. 20.

RomeIs, B, 1913 Der Einfluss versehiedenartiger Ernährung auf die Regeneration bei Kaulquappen (Rana esculenta) I. Arch. f. Entwicklungsmech., Bd. 37, p. 183.

VINCENT, S. 1912 Internal secretion and the ductless glands. London. 
All illustrations taken from living tadpoles. All figures in natural size except figures 10, $a$ to $i$ and $11, a$ to $f$.

\section{PLATE 1}

\section{EXPLANATION OF FIGURES}

1 , a to ze Rana temporaria I. Experiment I. $a$, liver; $b$, spleen; $c$, thymus; $d$, muscle; $e$, ovary; $f$, adrenal cortex; $g$, adrenal medulla; $h$, brain; June 6,1912 . $i$, liver; $k$, liver-thyroid; $l$, spleen; $m$, spleen-thyroid; $n$, muscle; $o$, muscle-thyroid; $p$, ovary; $q$, ovary-thyroid; $r$, adrenal cortex; $s$, adrenal cortex-thyroid; $t$, adrenal medulla; $u$, adrenal medulla-thyroid; $v$, brain; $w$, brain-thyroid; June 26, 1912. In $k, m, o, q, s, u, w$, thyroid feeding had been started on June 17, $1912 . \quad x$, liver; $y$, brain; $z$, spleen-thyroid; $z a$, muscle-thyroid; $z b$, ovary-thyroid; $z c$, adrenal cortex-thyroid; $z d$, adrenal medulla-thyroid; ze, brain-thyroid, July 6, 1912. In $z$ to $z e$, thyroid feeding had been started on June 17, 1912.

2, a to n Rana temporaria II. Experiment IV. a, original size, June 4, 1912. $b$, control; $c$, thyroid-muscle, thyroid given 1 day; $d$, thyroid-musele, thyroid given 3 days; $e$, thyroid-musele, thyroid given 5 days; June 17, 1912. $f$, thyroid-plants; thyroid given 1 day; $g$, thyroid-plants, thyroid given 2 days; $h$, thyroid-plants, thyroid given 4 days; $i$, thyroid-plants, thyroid given 5 days; $k$, thyroid-thymus; $l$, thyroid emulsion; June $17,1912 . m$, thyroid-thymus, $n$, thyroid-muscle; thryoid given 4 days; June 26.

3, a to n. Rana temporaria III. Experiment III. $a$, thymus; $b$, muscle; $c$, thymus-thyroid I; $d$, thymus-thyroid II; e, thymus-thyroid III; June 1, 1912. $f$, thymus-thyroid II; $g$, thymus-thyroid III; $h$, thymus-thyroid IV; June 17, 1912. $i$, thymus; $k$, thymus-thyroid V; $l$, muscle; $m$, muscle-thyroid; June $26,1912, n$, muscle-thyroid; July 6, 1912.

5, a to e Rana temporaria V to VII. Experiment VI. $a$, control; $b$, glandular hypophysis; June 26. $c$, control; $d$, glandular; $e$, neural hypophysis; July 6 , 1912.

6, a to d Rana temporaria V to VII. Experiment IX. $a$, control; $b$, thymusthyroid; June 17, 1912. $c$, control; d, thymus-thyroid; June 26, 1912. 
FEEDING EXPERIMENTS ON TADPOLES

J. F. GUDERNATSCH

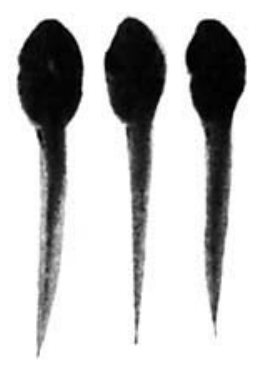

1 a

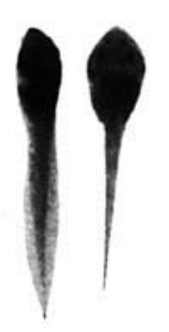

e

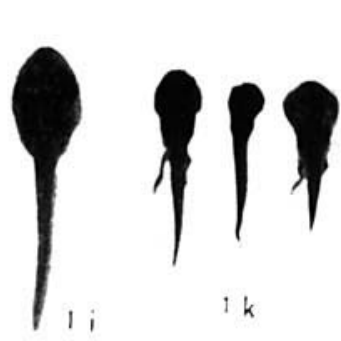

$1 f$

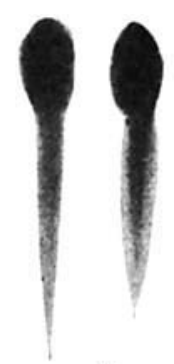

IC

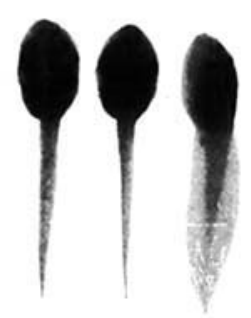

$1 \mathrm{~g}$

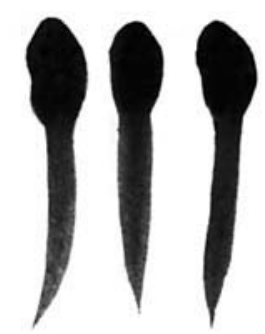

ld

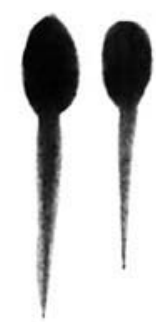

$1 \mathrm{~h}$
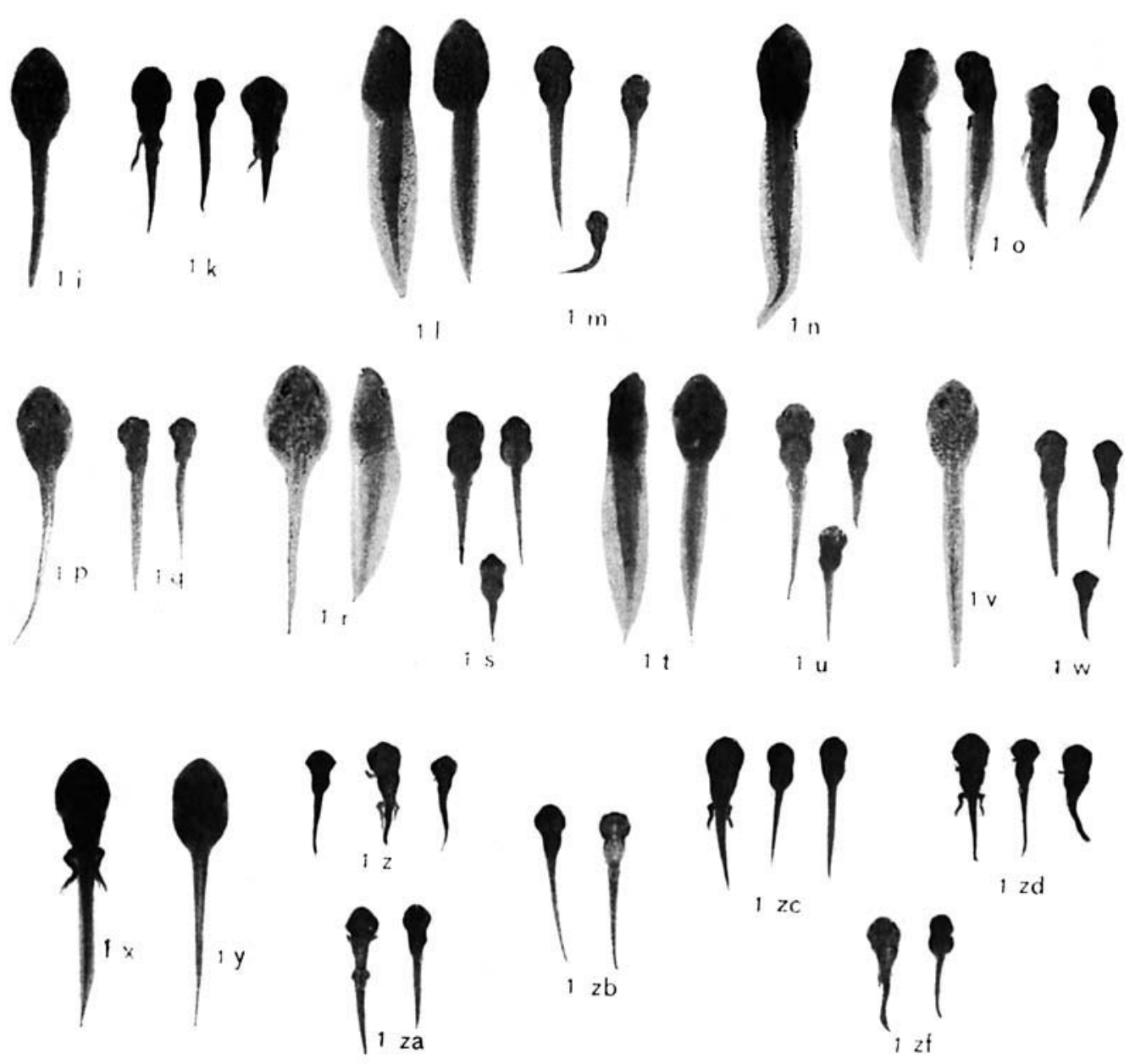

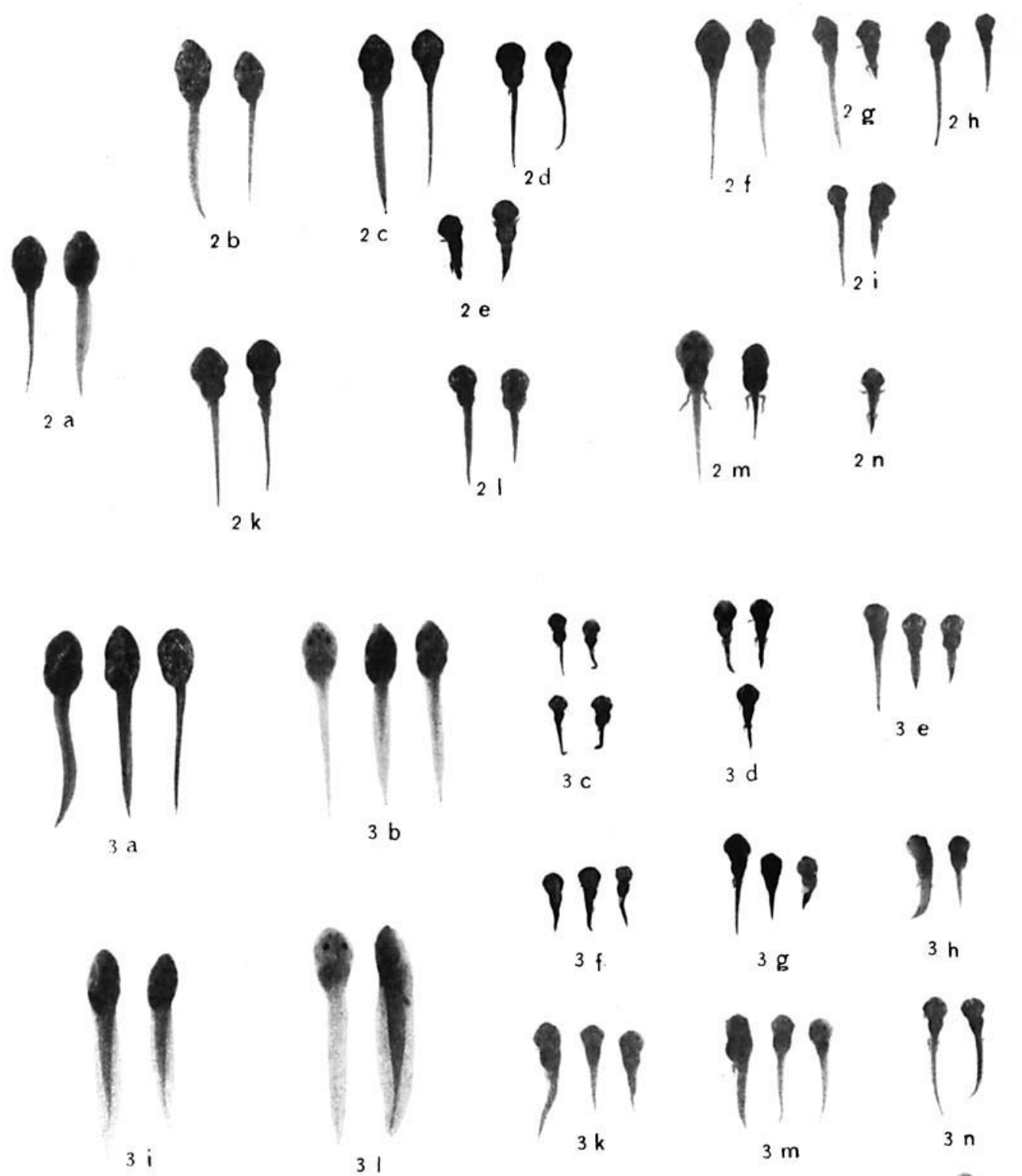

3 i
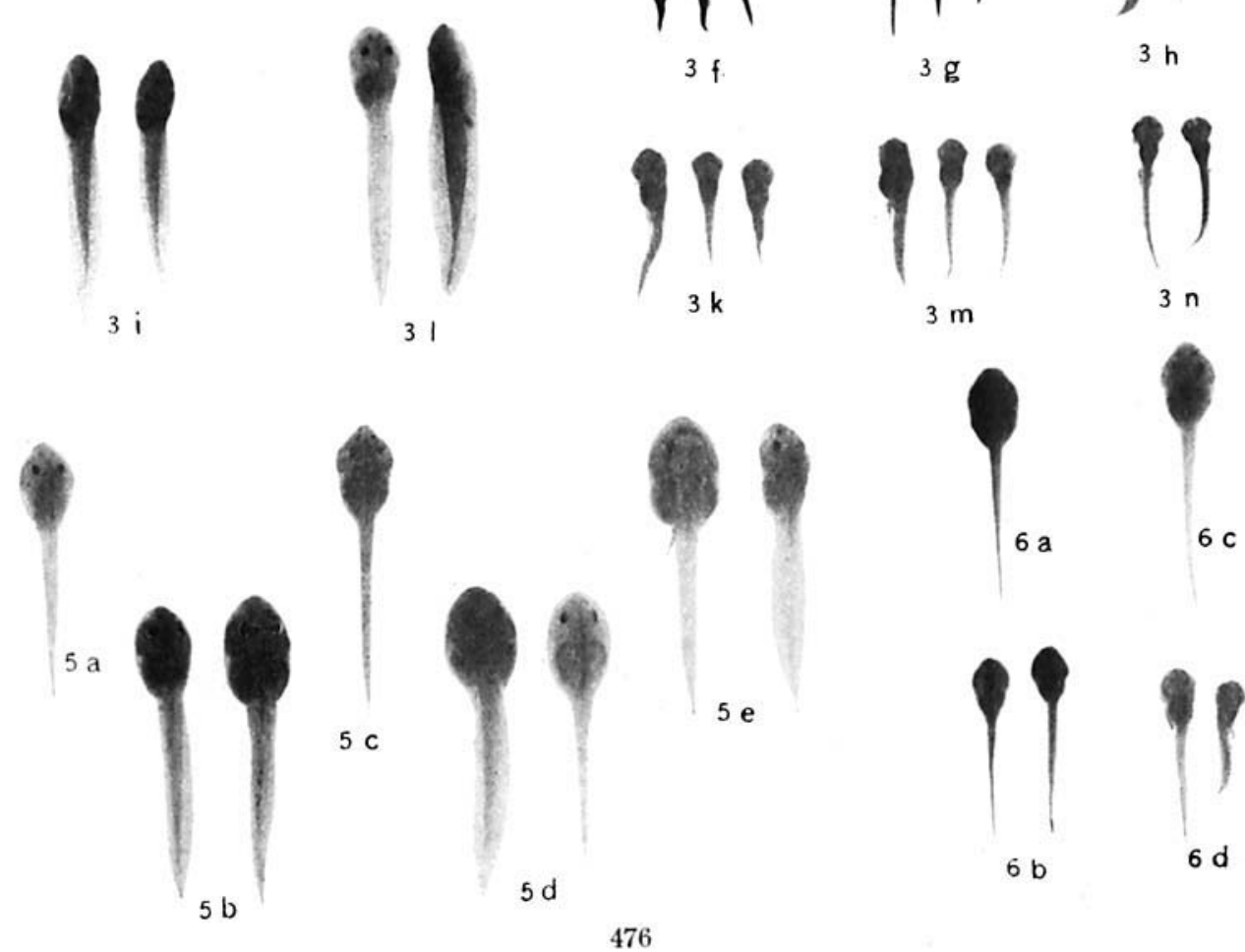
PLATE 2

\section{EXPLANATION OF FIGURES}

4, a to p Ranatemporaria IV. Experiment II. $a$, control; $b$, thymus; $c$, spleen; $d$, muscle (thyroid under $4, o$ and $p$ ) $; e$, thymus-thyroid II $; f$, thymus-thyroid III; $g$, thymus-thyroid IV; June 1, 1912. h, thymus-thyroid IV; $i$, thymus-thyroid V; June 17,1912 . $k$, muscle; $l$, muscle-thyroid; $m$, spleen; $n$, spleen-thyroid; June 26,1912 . o to $p, 1$ frog fed on liver, metamorphosing on July 12, and 5 pigmy frogs, fed on thyroid metamorphosing on April 22, 81 days earlier. o, dorsal; $p$, ventral view.

7 , a to $b$ Rana temporaria VIII to XI. Experiment V. a, spleen; $b$, adrenal; July 6, 1912.

8, a to d Bufo vulgaris I. Experiment VII. a, control; $b$, muscle; $c$, thymus; d, thyroid; June 6, 1912 .

9, a te $r$ Bufo vulgaris III. Experiment $X$. a, original size; June 5, 1912. $b$, control; $c$, thyroid-plants, thyroid given 1 day; $d$, thyroid-plants, thyroid given 3 days; $e$, thyroid-plants, thyroid given 5 days; June 26,1912 . I, thyroid-muscle; $g$, thyroid-plants (alternately); $h$, thyroid-thymus; $i$, thyroid-hypophysis; $k$. thymus-plants; $l$, thymus-hypophysis; June 26 , 1912. $m$, control; $n$, thyroidmuscle; $o$, thyroid-plants; $p$, thyroid-hypophysis; $q$, thymus-plants; $r$, thymushypophysis; July $6,1912$.

10, a to i Rana temporaria IV. Experiment II; compare figure 4, $a$ to $p$. Thyroid-fed frogs, 16 to 18 days old, at the time of metamorphosis, figure 4, $l$.

11 , a to f. Tails of tadpoles fed on different substances, to show pigmentation; figure 4, $l$. $a$ thymus; $b$, liver; $c$, spleen; $d$, musele; $e$, adrenal cortex; $f$. adrenal medulla. 
FEEDING EXPERIMENTS ON TADPOLES

J. F. GUDERNATSCH

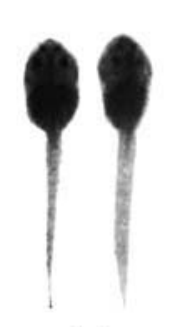

$4 a$

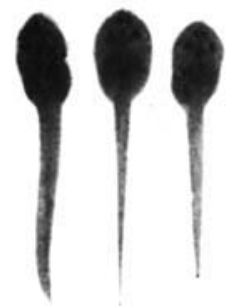

$4 \mathrm{~b}$

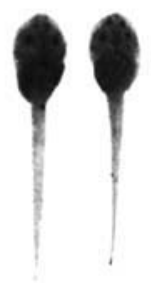

$4 \mathrm{C}$

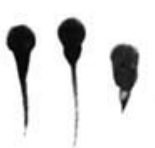

$4 \mathrm{~h}$

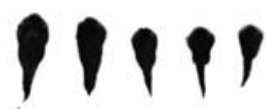

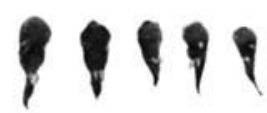

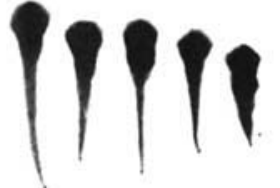

4 i
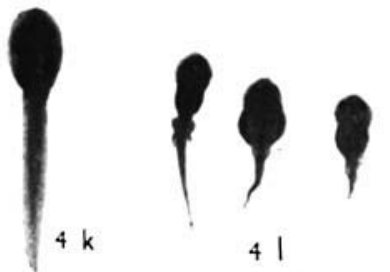

41
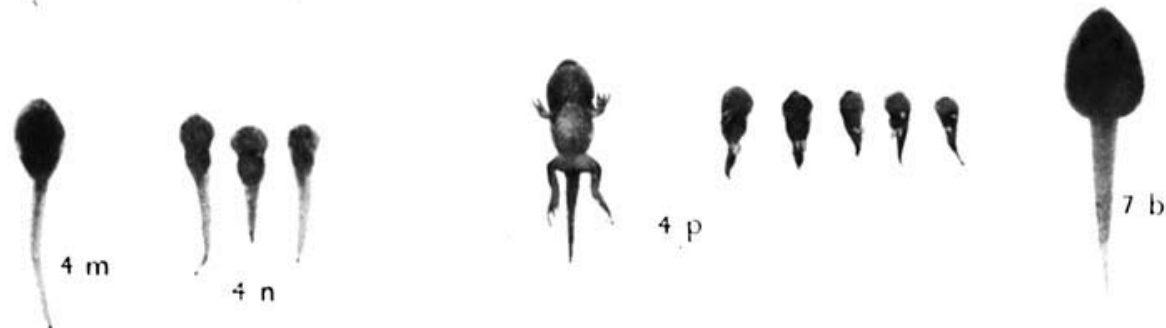

7 a

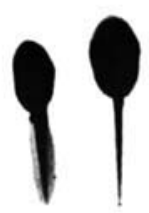

8 a

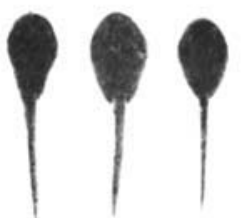

9 a

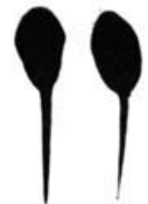

8 b

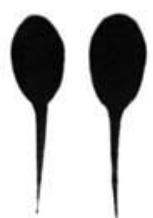

$8 \mathrm{c}$

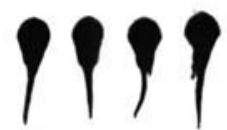

$8 \mathrm{~d}$
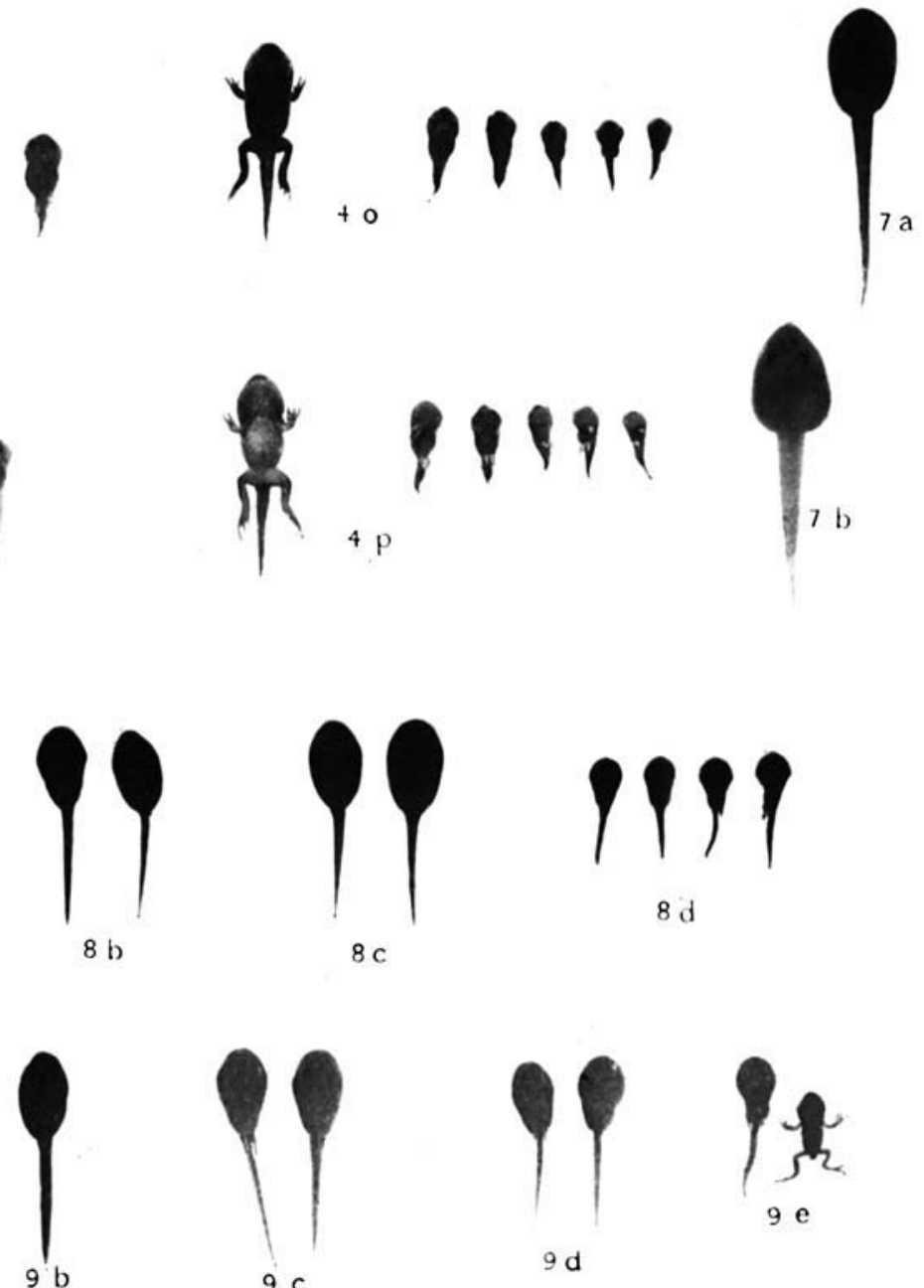

$9 \mathrm{c}$
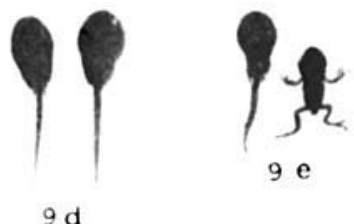

479 

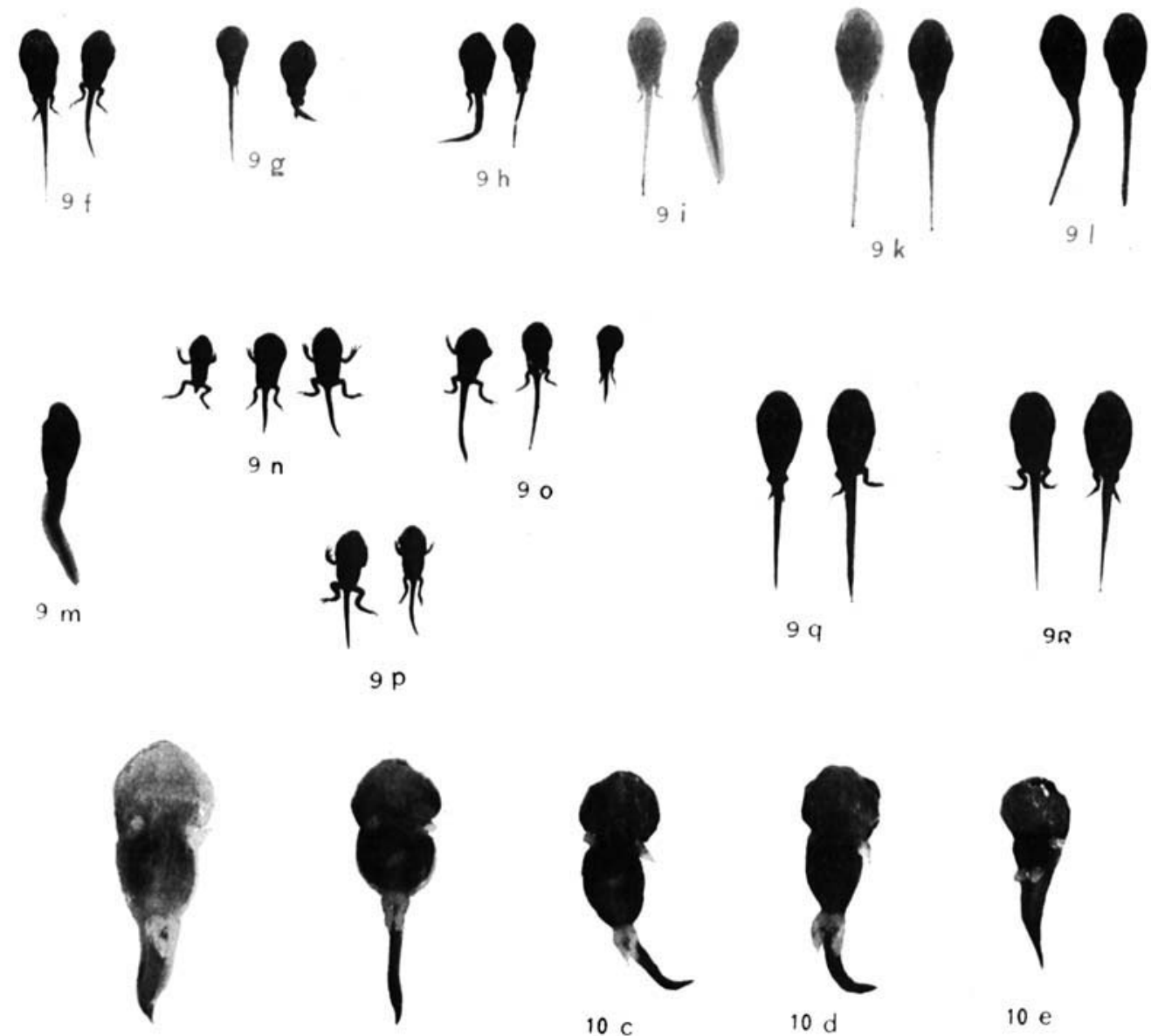

$10 \mathrm{a}$ $10 \mathrm{~b}$

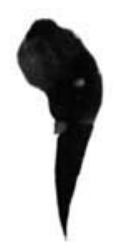

$10 f$
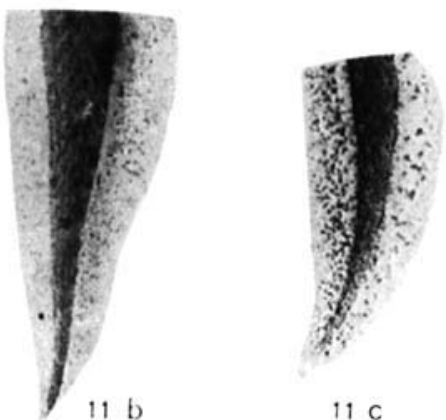

$11 \mathrm{C}$

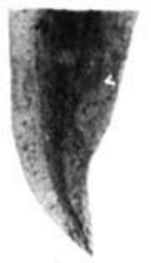

$11 \mathrm{~d}$

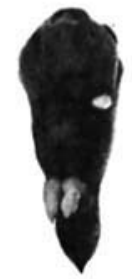

$10 \mathrm{~h}$

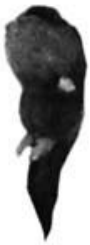

$10 \mathrm{i}$

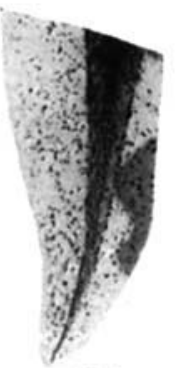

$11 \mathrm{e}$

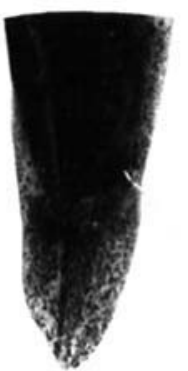

$11 \mathrm{a}$

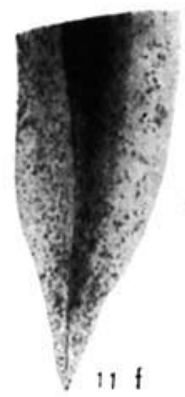

